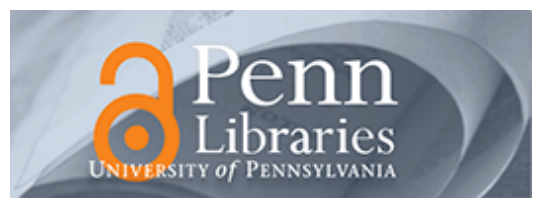

University of Pennsylvania

ScholarlyCommons

Management Papers

Wharton Faculty Research

3-1-2016

\title{
Enacting a Constellation of Logics: How Transferred Practices Are Recontextualized in a Global Organization
}

\author{
Sara Varlander \\ Stanford University \\ Pamela Hinds \\ University of Pennsylvania \\ Bobbi Thomason \\ University of Pennsylvania \\ Brandi M. Pearce \\ Stanford University \\ Heather Altman \\ Stanford University
}

Follow this and additional works at: https://repository.upenn.edu/mgmt_papers

Part of the Management Sciences and Quantitative Methods Commons

\section{Recommended Citation}

Varlander, S., Hinds, P., Thomason, B., Pearce, B. M., \& Altman, H. (2016). Enacting a Constellation of Logics: How Transferred Practices Are Recontextualized in a Global Organization. Academy of Management Discoveries, 2 (1), 79-107. http://dx.doi.org/10.5465/amd.2015.0020

At the time of publication, authors Pamela Hinds and Bobbi Thomason were affiliated with Stanford University. Currently, they are faculty members at the Wharton School at the University of Pennsylvania.

This paper is posted at ScholarlyCommons. https://repository.upenn.edu/mgmt_papers/192

For more information, please contact repository@pobox.upenn.edu. 


\title{
Enacting a Constellation of Logics: How Transferred Practices Are Recontextualized in a Global Organization
}

\begin{abstract}
We explore how new practices are transferred across locations in a global organization. The company we studied strove to infuse more user-centered innovation and quicker, more agile delivery of software into their development teams. The practices for doing so were crafted in the United States and then transferred to China and India. Over a period of 20 months, we observed how three practices were transferred to and enacted at each location. Our findings suggest a constellation of logics, which varied by site and by practice, molded the particular recontextualizations at each site. We contribute to a deeper understanding of how employees experience and respond to the transfer of practices from abroad by proposing that a constellation of logics guides recontextualization of meaning as well as action. Our empirical work and analysis also raises numerous questions about the effects of the recontextualizations on performance, what makes a particular logic or constellation of logics salient for a particular practice at a particular time, the stability and malleability of these logics, and what happens in global collaborations when different logics are invoked at different locations.
\end{abstract}

\section{Keywords}

recontextualization, institutional logics, transfer of practice, adaptation, translation, institutional complexity

\section{Disciplines}

Management Sciences and Quantitative Methods

\section{Comments}

At the time of publication, authors Pamela Hinds and Bobbi Thomason were affiliated with Stanford University. Currently, they are faculty members at the Wharton School at the University of Pennsylvania. 


\title{
Enacting a Constellation of Logics: How Transferred Practices are
}

\author{
Recontextualized in a Global Organization
}

\author{
Sara Vaerlander \\ Pamela Hinds \\ Bobbi Thomason \\ Brandi Pearce \\ Heather Altman \\ Center for Work, Technology and Organization \\ Department of Management Science \& Engineering \\ Stanford University \\ Stanford, CA 94305-4026 \\ Contact Email: phinds@stanford.edu
}

\begin{abstract}
Acknowledgements: The authors thank SAP Labs, Silicon Valley, China, \& India for their support for and participation in this study. In particular, Sam Yen, Philipp Skogstad and Li Gong were instrumental in paving the way for this work, providing regular updates, and answering our questions. We also thank the members of the Center for Work, Technology \& Organization (WTO) and Soon Ang, Associate Editor, and the reviewing team at AMD for their helpful comments as we developed this work.
\end{abstract}




\title{
Enacting a Constellation of Logics: How Transferred Practices are Recontextualized in a Global Organization
}

\begin{abstract}
We explore how new practices are transferred across locations in a global organization. The company we studied strove to infuse more user-centered innovation and quicker, more agile delivery of software into their development teams. The practices for doing so were crafted in the US and then transferred to China and India. Over a period of 20 months, we observed how three practices were transferred to and enacted at each location. Our findings suggest a constellation of logics, which varied by site and by practice, molded the particular recontextualizations at each site. We contribute to a deeper understanding of how employees experience and respond to the transfer of practices from abroad by proposing that a constellation of logics guides recontextualization of meaning as well as action. Our empirical work and analysis also raises numerous questions about the effects of the recontextualizations on performance, what makes a particular logic or constellation of logics salient for a particular practice at a particular time, the stability and malleability of these logics, and what happens in global collaborations when different logics are invoked at different locations.
\end{abstract}




\section{INTRODUCTION}

With the expansion of multinational firms, organizations face a dilemma regarding the extent to which strategic organizational practices should be replicated across locations. On one hand, having shared practices reinforces a common corporate culture and enables the deployment of unique programs that give organizations a competitive advantage. On the other hand, practices that are effective and appropriate in one local context may be ineffective, impractical, or even illegal in others. Research on the global transfer of practices suggests that organizations are faced with "institutional duality," a condition in which subsidiaries of global firms operate in the institutional environments of both the multinational firm and the country in which they are located, thus creating rival pressures from these locations as the subsidiaries try to meet competing demands (Kostova, 1999; Kostova \& Roth, 2002).

To date, researchers have explored the meaning of institutional duality for organizations and their subsidiaries, suggesting that, as a result, adoption of practices may be ceremonial (Kostova \& Roth, 2002) or hybridized (Ferner, Edwards, \& Tempel, 2011), rather than reflecting full compliance and internalization (Winter, Szulanski, Ringov, \& Jensen, 2012). Researchers, for example, have argued that practices are subject to translation or editing (Czarniawska \& Sevón, 1996; Saka, 2004; Frenkel, 2005; Morris and Lancaster, 2006; Sahlin \& Wedlin, 2008), glocalization (Gond and Boxenbaum, 2013), recontextualization (Brannen, 2004), and adaptation (Ansari, Fiss and Zajac, 2010; Canato, Ravasi and Phillips, 2013; Ferner et al., 2011), which suggest that as practices are transferred to new geographical contexts they take on new meanings and "acquire[s] elements characteristic of the host setting" (Ferner et al., 2011, p. 16) (e.g., Szulanski \& Jensen, 2006). The expectation is that some level of adaptation is necessary to assure a cultural, political and technical fit with the local context (Ansari et al, 2010). This view 
promotes an understanding of practices themselves as moldable as they move into new geographical contexts.

Even though research has started to provide insight into the process of cross-national transfer of practices, important gaps remain. First, nearly all of the research thus far has been conducted at the field or industry level rather than the intra-organizational level (see Ansari, Reinecke and Spaan, 2014). As Gondo and Amis (2013, p. 229) note, "our understanding of what happens within organizations when new practices are adopted remains at a distinctly nascent stage." As a result, little is known about how overseas locations within the same organization experience and respond to the transfer of practices, and whether and how the prescribed practices evolve to fit these diverse contexts. Second, although scholars have begun to study how practices are adapted (Ansari et al, 2014; Gond and Boxenbaum, 2013), much of this work focuses on managerial strategies (e.g. Ansari et al, 2014), so a gap remains in our understanding of the experience and activities of those enacting the practice. Finally, there has been some discussion of the fit or misfit of practices with the recipient context (e.g. Ansari et al., 2014), but how the fit is determined by those enacting the incoming practices remains underexplored. As a result, we do not know how, within the same organization, units enacting practice transfers from abroad make sense of those practices and how this affects adaptation (or absence of adaptation) of the practices.

\section{WHAT EXISTING THEORY TELLS US ABOUT ADAPTATION}

Practice scholars have conceptualized practices in a variety of ways. For the purposes of this study, we borrow from Schatzki, who defines practices as "embodied, materially mediated arrays of human activity centrally organized around shared practical understanding” (Schatzki 2001: 2). Thus, the notion of practices focuses on patterns of behaviors within a situated context. 
Recent studies on the global transfer of practice have examined whether adaptation leads to positive or negative outcomes, the fidelity of the transfer, antecedents to successful transfers and, to a lesser extent, how transfer and the adaptation of practices occurs. In some sense, multinationals are torn between rolling out practices consistently for strategic advantage and adapting practices to specific geographies to ensure alignment with the local context (see Kostova \& Roth, 2002). Historically, research on the transfer of practices has equated "successful" transfers with transfers of high fidelity, that is, identical to that of the sending context. Jensen and Szulanski (2004), for example, found that adaptations to the local context contributed to difficulties in cross-national transfers of practice. Although focused on collaboration between distant locations rather than on the transfer of practice, Nicholson and Sahay's (2001) study of outsourcing from Britain to India also tells us that local views of software development as an art (Britain) as compared to an engineering activity (India) can affect the way that software development practices are interpreted and enacted.

Over the years, however, scholars have challenged the contention that high fidelity transfers are optimal. Kostova and Roth (2002), for example, in a survey-based study of subsidiaries of a large US multinational corporation, show that quality management practices transferred from headquarters were often adopted ceremonially and not fully internalized by subsidiaries. "Ceremonially adopted practices" have the veneer of adoption, but the beliefs and values underlying the practices are not assimilated. They argue that, particularly with strategic organizational practices, which are "dominant, critical, or crucial for achieving the strategic mission of the firm," success depends on the transferability of meaning and value, not merely the transfer of knowledge (e.g. Kostova, 1999: 308). Studies have also shown that when practices are transferred across locations, they tend to be reconstituted as they are enacted by 
organizational members (Czarniawska \& Sevón, 1996; Gond and Boxenbaum, 2013; Sahlin \& Wedlin, 2008). In her detailed examination of Walt Disney Company's attempts to transfer theme park practices from the US to Japan and France, for example, Brannen (2004) describes how transferred "assets" took on new meanings through "recontextualization," which she articulates as a process through which individuals adapt the meaning of a practice to their own context. Specifically, Brannen shows the importance of historical, political, and cultural contexts to how recipients decode the meaning of the practice being transferred. Brannen and others have argued that a lack of adaptation of meaning to the local context can lead to dramatic failures. For example, English law firms' attempts to transfer practices to Italy, without alteration, failed because the firms found themselves out of alignment and in conflict with local regulatory, normative, and cognitive expectations (Muzio \& Faulconbridge, 2013). Although not focused on a global transfer of practice, Canato, Ravasi and Phillips (2013) studied the implementation of a Six Sigma practice at 3M when there was a misfit between the practice and the organization's culture. They found that implementation of the practice required mutual adaptations in the practice and the organizational culture. Taken together, evidence strongly suggests that adaptation of practices is necessary for the successful transfer of practices to new national contexts.

Scholars have also explored antecedents to successful adaptations of practices from abroad. Taking a management perspective, Ansari and colleagues (2014) identified strategies that organizations employ to actively manage adaptation and carefully engineer the transfer process. In their study of the adaptation of Six Sigma practices in US and Korean companies, Yu \& Zaheer (2010) examined conceptual, social, and technical underpinnings of the organizational practice and report that more social practices (e.g., the amount of social interaction demanded by 
the practice) increase the extent to which a practice is influenced by national-level contextual variables. In other words, practices that are more social demand more local adaptation. Brannen (2004) also argues that "soft" technologies, such as personnel practices, are more likely to be recontextualized.

Although nascent, there are also several studies that begin to illuminate the dynamics of how adaptation occurs in the transnational transfer of practices. In their field-level study of the diffusion of responsible investment practices in France and Québec, for example, Gond and Boxenbaum (2013) report three types of activities which they call contextualization work filtering, repurposing, and coupling. Filtering work refers to activities that involve the minimization or elimination of features of the practice that are incongruent with the new context. Repurposing is the changing of meaning or application of a practice to align with the receiving context. Coupling refers to actors integrating the new practice with existing practices or objects that are already seen as locally legitimate. According to Gond and Boxenbaum, each of these facilitates the acceptance of the practice into the new context. Focusing on the adaptation of management innovation practices to their context, Scarbrough, Robertson and Swan (2015) studied the global diffusion of resource planning and show how "carriers and hosts co-construct management practices diffusing into new settings" (Ansari, Fiss and Zajac, 2010, p. 86 in Scarbrough et al, 2015). Particularly, they underline the critical role of agency both at the fieldlevel where innovation is continuously reframed discursively, and by organization-level actors who enacted and adapted the innovation to the organizational contexts.

In sum, studies examining the cross-national transfer of practice establish the critical role of adaptation and shed light on factors that affect adaptation as well as how it can be managed. Evidence also indicates that individuals are actively engaged in the adaptation process. Despite 
these advances, our understanding of how adaptations occur, especially at the intraorganizational level, and the micro level processes involved remains limited. In particular, we know little about how those enacting them make sense of practices coming from company locations abroad. Recent research has employed the idea of institutional logics to describe how people and organizations make sense of and import ideas and practices. Early evidence from existing research suggests that institutional logics may illuminate the process of how practices are transferred globally.

\section{Institutional Logics and the Transfer of Practice}

Logics are generally understood to be belief systems located at the macro level that shape actors' cognitions and actions at the field level. Institutional logics have been defined as the “socially constructed, historical patterns of material practices, assumptions, values, beliefs, and rules by which individuals produce and reproduce their material subsistence, organize time and space, and provide meaning to their social reality" (Thornton \& Ocasio, 1999: 804). Logics are imbued with values and principles that guide attitudes and behaviors (see Thornton, 2004; Thornton, Ocasio, \& Lounsbury, 2012) and are "embodied in practices that are sustained by and reproduced through cultural rules, norms, and beliefs" (Lok, 2010: 1308; see also Thornton \& Ocasio, 2008). This link between logics and practices has been well established (e.g., Greenwood et al., 2010; Greenwood et al., 2011; Lounsbury, 2007; Zilber, 2006). Zilber (2002), for example, in her study of a rape crisis center in Israel, showed that practices were infused with meanings associated with both feminist and therapeutic logics. Smets, Morris, \& Greenwood's (2012) study of a merger of an English and a German international law firm also illustrates how members at the two sites were guided by largely different logics - the expertise/client-service and fiduciary logics, which prescribed different values and practices. These studies establish the 
role of logics in informing practice.

Although not global, several studies using the lens of institutional logics have further established that practices (and their transfer) are rooted in different geographic locations (Greenwood et al., 2010; Lounsbury, 2007). Through his study of logics relating to mutual funds in Boston and New York, Lounsbury (2007), for example, established that multiple logics related to efficiency and performance, which were sometimes tied to geographic location, affected where and how practices spread. In a study drawing on data from the Spanish manufacturing sector Greenwood and colleagues (2010) show that a combination of local conditions (concentration of branches) and regional policies (spending on industrial development) heavily influence the logics embedded in local communities (in their case, related to the decision to downsize), and argue that "the richness of local processes may have been significantly underestimated" in research on institutional logics (535). In a study of business group restructuring, Chung and Luo also document how governance models are institutionalized at the national level "because of their historically path-dependent development in the unique cultural and political configurations of their own national contexts" (2008: 768). They show, for example, how an institutional logic of family control influenced corporate governance models in Taiwan. Thus, growing evidence suggests that different geographic locations likely hold different and potentially incompatible logics which may, in turn, affect how practices evolve. We posit, therefore, that one body of research that can elucidate the transfer process is recent work on institutional logics - especially cases in which multiple logics are at play, as they may be when transferring practices within an organization and across national borders.

Over the last decade, research has increasingly focused on complex institutional environments in which organizations are faced with multiple, often competing, logics (e.g., 
Greenwood, Diaz, Li, \& Lorente, 2010; Greenwood et al., 2011; Seo \& Creed, 2002; Thornton \& Ocasio, 2008). Pluralistic environments impose conflicting demands and pressures on organizations (Kraatz \& Block, 2008; Greenwood, et al., 2010; Jarzabkowski, Smets, Bednarek, Burke, \& Spee, 2013) and force organizations and their members to selectively, consciously or unconsciously, enact one or more logics to achieve their goals. Dunn and Jones (2010), for example, studied medical schools that drew on health care and academic logics. Powell and Sandholtz (2012) studied biotechnology companies that incorporated science and market logics, and Pache and Santos (2013a, 2013b) studied competing social welfare and commercial logics. The gist of this research is that multiple logics are not always compatible (Greenwood et al., 2010) and the more diverse the logics, the greater the challenges an organization confronts (Besharov \& Smith, 2012).

Studies have further established that organizational actions are influenced by potentially competing logics and many organizations face enduring complexity where, rather than one dominant logic winning, multiple logics co-exist for extended periods (see Greenwood et al., 2011). Dunn and Jones (2010), for example, show how the logics of care and science interacted with societal changes, such as the rise of managed care and the increase of women in the profession, and influenced the delivery of medical education over a 38-year period. Goodrick and Reay (2011), based on their study of the pharmacist profession in the US, introduce the idea of a "constellation of logics" to capture situations in which a combination of logics guide the behavior of actors. Their study was among the first to document a situation in which different logics sustained overtime in professional work.

\section{Micro-Level Responses to Complex Institutional Environments}

Although scholars have shown an interest in understanding the characteristics, evolution, 
and challenges in industries characterized by complex institutional environments, much less research investigates what happens at the micro-level of organizations in a pluralistic environment. Thornton, Ocasio, \& Lounsbury (2012) recently underlined the need for a deeper understanding of the microfoundations of logics, and scholars have just begun to explore how logics are enacted and play out in the everyday lives of organizational members. In a pioneering study, Reay and Hinings (2009), for example, report how organizational actors in the Alberta Health Care sector conducted their day-to-day work in a context of multiple logics. They allude to how physicians and managers can maintain their independence and simultaneously collaborate despite drawing on different logics. Pache and Santos (2013a) take an additional step towards micro-level processes by exploring how organizational members experience conflicts and enact individual responses; they suggest competing logics create the latitude for individual action. McPherson and Sauder (2013) also report agency in actors' everyday use of logics. They examine the ways professionals used logics to negotiate decisions in a drug court with four distinct orientations: the logics of criminal punishment, rehabilitation, community accountability, and efficiency. They show how actors employ logics in their micro-level interactions, bring logics from a societal level down to the field level, and actualize logics in practice. Drawing on the toolkit approach (Swidler, 1986), McPherson and Sauder (2013) highlight that logics are constructed, transmitted, and used by people with interests, beliefs, and preferences-leading to actors employing different logics at different times, and using the same logic to achieve different goals, depending on the situation. They state that "conceiving of logics as tools reveals how they can be continuously combined, configured, and manipulated to serve the purposes of actors" (2013: 4). In the drug courts they studied, actors hijacked the logics of other groups to establish legitimacy. Lok (2010) also examines identity work of management and institutional investors 
faced with a shift in the logic of shareholder value. He shows that executives used ambiguities and contradictions to reconstruct their identities "in ways that qualified and specified the meaning and jurisdiction of the logics of enlightened shareholder value in their every day practices" (2010: 1330).

In a more direct examination of how individuals respond when they encounter new competing logics, Pache and Santos (2013b) outline five strategies that individuals may employ: ignorance, compliance, defiance, combination, and compartmentalization. Combination and compartmentalization reflect types of adaptation, but ignorance, compliance, and defiance do not. Aligned with Pache and Santos' (2013b) notion of compartmentalization, Murray (2010) argues that conflict between multiple logics does not necessarily always present challenges of compatibility. Instead, in hybrid contexts, individuals can engage in strategies to preserve the distinctiveness of particular logics, thus allowing for multiple logics to reside side-by-side. Although most of the forgoing studies have not examined logics across national boundaires, Luo (2007) offers one exception. In her micro-level cross-national study, Luo examined attitudes toward training in multiple countries and found that national institutional logics affected workers' attitudes through direct cognitive effects, goals, and structure of the incentive systems. This study provides evidence that the logics employed may vary across national boundaries, although it stops short of articulating how logics shape practice.

Overall, research on micro-level responses to complex organizational environments indicates that workers have agency and use improvisations, especially when the meaning of logics are ambiguous and contradictory, to interpret and enact different logics at different times in a way that aligns with their interests. Nevertheless, to date, little attention has been devoted to the practices of members working within a context characterized by institutional complexity 
(Jarzabkowski, Matthiesen, \& Van de Ven, 2009) and how organizational members, even within the same organization, can invoke logics to make sense of transferred practices. Particularly, gaps remain in our knowledge about how this happens across geographies, especially in a multinational setting.

In summary, research on the global transfer of practices and related inquiries show that adaptation of practices may be necessary to enable new practices to thrive in these diverse, multiple, and fragmented settings and that logics can be rooted in geographic locations. At the micro-level, there is also strong evidence of agency, suggesting that actors and groups of actors make use of different logics to establish and maintain legitimacy when embedded in contexts with multiple incompatible logics. Questions that remain open, and that we address in our research, revolve around how adaptations occur and what influences the form that they take, especially from the perspective of units confronted with the day-to-day exigencies of multiple logics in complex institutional settings. In the absence of longitudinal studies of the transfer of practices across international contexts, one of our contributions is to show how employees make sense of, and respond to, a new set of practices transferred from vastly different institutional contexts.

\section{METHOD}

Our empirical data stems from a longitudinal ethnographic study at InnoTech (a pseudonym), a large multinational software development company. In 2011, InnoTech decided it was time for an intellectual renewal of the organization. In order to realize this renewal, the leadership team argued that employees needed to change their work methods and "acquire a new mindset." To achieve this, top management promoted Innovation Centers that would incorporate Agile methodology and innovation practices. Agile methods call for a more dynamic software 
development process. In short, Agile methods

are characterized by short iterative cycles of development driven by product features, periods of reflection and introspection, collaborative decision making, incorporation of rapid feedback and change, and continuous integration of code changes into the system under development working together on rapid prototyping with continuous customer involvement to identify requirements as they emerge so that they can respond to change quickly. (Nerur, Mahapatra, \& Mangalaraj, 2005: 75)

These values promoted a largely different work process compared with the highly structured waterfall models of software development upon which InnoTech had traditionally relied. In addition, the Innovation Centers had a strong focus on "design thinking" - an approach to innovation characterized by being human-centered, iterative, and collaborative.

The US was the first location to roll out the new "Innovation Center," a few miles away from the main US campus. Separation from the main campus was considered necessary to facilitate a change in work practices and mindset, and to "mentally take a break from the [InnoTech] prison" (Interview, Manager). Within a few months, Innovation Centers were also rolled out at the Chinese and Indian locations, and subsequently at handful of other locations. At each site, the rollout of the Innovation Center was initiated with an onsite 3-day workshop held by representatives from the US InnoTech management team where the basic principles of agile methodology and design thinking were introduced. The first workshop was held at the US Innovation Center, followed by the Chinese and finally the Indian site. The global rollout of the Innovation Centers created an ideal context to study the global transfer of practices. In this paper, we focus on how the new Innovation Center work practices were implemented at the US location and transferred to newly established Chinese and Indian Centers. Our sites can be seen as an extreme case (Eisenhardt and Graebner, 2007) of geographic dispersion, with sites located in different parts of the world. These extreme cases allowed for theoretical development since 
they enabled strong contrasts and facilitated visibility into divergent patterns.

\section{Data Collection}

In this study, we followed the rollout of the Innovation Centers at the three sites during 20 months between January 2011 and September 2012, relying mainly on observational fieldwork and interviews. We also conducted preliminary interviews at InnoTech's German and several other sites to better understand what the new practices, especially agile methodologies and design thinking meant to InnoTech. In summer 2011, we initiated our ethnographic data collection. We started our research at each site in conjunction with the opening of their Innovation Center, which allowed us to capture the initial experiences of team members and observe how practices evolved over time.

We went into the field with the intent to follow a development project at each site from beginning to end. Project teams that were part of the Innovation Centers were composed of 7 to 10 members, including a mix of developers and designers. While at the sites, we focused on the project teams, but also conducted interviews and observations with most members of the Innovation Centers at each location. Our focus was broadly to grasp work practices as they transferred to the Innovation Centers. A typical field day lasted 5 to 10 hours and involved observing the Centers' work practices, such as individual work, project interactions, and project meetings; informal interactions, such as coffee chats and lunches; and structured interviews. We also attended numerous conference calls and joined the Center members at social events. These observations were important to gather behavioral data, and detect how members enacted the new work practices at different sites. See table 1 for a schedule of observations and informant characteristics by location. 
During data collection, we continuously took field notes. In total, we spent 92 days in the field; each day generated 5 to 15 typed pages of notes, which were completed within 12 hours of the observation. We also took numerous photos at each site to remember details of the context, such as artifacts, workspace arrangements, and ways of interacting. Our approach also involved informant interviewing and an "interweaving of looking and listening, of participating and asking” (Lofland \& Lofland, 2006, p. 18). We conducted formal semi-structured interviews as well as had informal conversations with organizational members. To understand a variety of perspectives, we conducted 57 interviews with organizational members from different roles and functions within the organization. Most interviews took place face-to-face, and the questions were open-ended to allow elaboration, discussion, and for unexpected issues to emerge.

Although we modified the interview protocol throughout data collection to make sure we grasped emerging themes (Spradley, 1979), common to each protocol were questions about members' (1) professional background and experience, (2) understanding and experience of the work practice in the Innovation Center, and (3) typical work day. During the entire data collection period, we maintained an informal relationship with several team members and managers. This was vital for us to remain informed about organizational changes and evolving experiences of those at the Centers, especially while we were away from them.

\section{Data Analysis}

Analysis of the data followed a grounded theory approach (Strauss \& Corbin, 1998). In the first stage, we conducted data collection and analysis iteratively by identifying important issues from the interviews and the observations (Eisenhardt, 1989) and delving deeper in subsequent observations and interviews. As an example, after each day of observation or interviews, we identified and summarized key issues so that we could bring these new 
understandings into the subsequent observations and interviews (Ezzy, 2002; Yin, 2008). In the field, each researcher also wrote memos reflecting emerging areas of inquiry, which they shared with the rest of the research team. This procedure enabled us to continually refine the interview questions and, in subsequent interviews, focus on key insights as they emerged.

In the second stage, we conducted open coding (Strauss \& Corbin, 1998). At this point, multiple authors used NVivo to code all of the data across all locations to identify emerging themes. A few examples of open codes were "use of space," "meaning of agile," "practices of customer interaction," "practices of shortened development time frame," It became apparent at this stage that the different Innovation Centers diverged in their interpretation of many of the practices associated with agile methods and design thinking. Our next step was then to identify key practices and code each practice by location. The combination of agile and design thinking led to a handful of practices that, from a managerial perspective, characterized the Innovation Centers. In our analysis, three practices emerged as being particularly salient across locations the 90-day cycle, user-centered design and open collaborative spaces. In short, the 90-day cycle represented InnoTech's commitment to dramatically reduce development time for market-ready software applications by shifting from the yearlong development cycles InnoTech had traditionally used. User-centered design specified that users should be involved early on and throughout the software development process. Finally, the open collaborative spaces dictated the replacement of the former cubicle arrangements with an open and flexible space in which individuals with different roles were co-located together rather than being separated, as had traditionally been the case at InnoTech.

As we analyzed our coding by practice across locations (e.g. examining all data related to the 90-day cycle in the US, China, and India) it became clear that there was variation across sites 
in terms of how they engaged with each of the three practices. In order to capture this variation in a more fine-grained manner, in a third round of coding we iterated with the literature on the transnational transfer of practice and, ultimately, on institutional logics to understand how and why these practices varied across sites. At this stage, it became clear that each site drew on different meaning systems to make sense of the practice and guide their actions. As we iterated between the data and the scholarly literature, trying out different lenses, it became clear that the notion of institutional logics could help us understand why recontexualization varied across sites. It was particularly apt at helping us to understand why practices were enacted differently and capturing how the local meaning systems at each site were employed. We again coded the data by practice by location and captured the way that members at each location made sense of each practice. In some cases, the logics on which they drew mapped to logics previously discussed in the literature (e.g. the market logic). In others, the logic was not familiar, so we labeled it as a new logic (e.g. the engineering logic). We examined both meanings and actions associated with the practices, which gave us a deeper understanding of the variation that occurred across sites and led us to uncovering various forms of recontextualization. These were manifested in the vastly different behaviors and meanings that emerged at each site as members enacted the transferred practices.

\section{FINDINGS}

As mentioned earlier, the 90-day cycle, user-centered design, and open collaborative spaces emerged as particularly salient practices in the Innovation Centers we studied. In their efforts to transfer these practices, the US location begun with a 3-day workshop prior to the opening of each new Center. Periodically, one of the leadership teams from the US also visited the China and India Centers to assess the implementation and address questions and issues that 
arose. These individuals resembled the 'mediators' that Orlikowski et al (1995) refer to, and similarly, helped users to incorporate the new practice by "providing advice, demonstration, and hand-holding" (p. 440). Although there was some acceptance on the part of management that adaptation would be necessary, there was also a desire for reasonably high-fidelity transfers. Despite this, we noticed divergence in each of these practices and how they were made sense of and enacted in the US, China, and India.

\section{The 90-Day Cycle}

The "90-day cycle" was one of several key practices associated with the Innovation Centers. Top management argued that entrepreneurs, and even student teams, were able to put applications into the market in a few months, so InnoTech should be able to do the same.

The former practice involved getting products to market within a considerably longer 18-36 months time frame. As one manager said when discussing past problems:

In other words, we brought it too late and then the wrong thing.[...]for 36 months, you can do a lot of planning, you can keep a lot of people busy planning. But it also slows things down. And so, initially the intent was to put pressure on reduce the planning, just iterate quickly... so speed the company up. Do real work. Throw it at the walls. See what sticks, what is good. Keep it moving.

Management told us that the 90-day cycle aimed at resolving this situation and having "feedback come in very quickly" instead of doing more internal testing and planning. They also argued that the reduced timeframe was a way to minimize complex interdependencies between developers and resolve problems earlier. As one manager explained:

Assuming I have 100 developers working, if I have 100 developers working for 1 day, I need to only plan 1 day worth of dependencies that they touch. If I have them working 10 days, I need to have 10 days' worth of dependencies. Way more. If I have 100 days.... So, you get the point. It goes up exponentially.

All locations were accustomed to extended (18-36 month) development cycles that were planned in detail using a traditional waterfall method. Our study revealed that for the teams in the US, 
China, and India, the 90-day cycle came to mean different things and resulted in different enactments of the practice.

Enactment of the 90-day cycle at the US site. The US team members viewed the 90day cycle as a vehicle to jumpstart more innovative processes and felt they had the agency to do what was needed. The 90-day cycle, for example, was described as fostering a new organizational structure with more flexibility. Echoing this widespread view, one designer described the 90-day cycle as offering a looser structure, in which teams had the discretion to distribute tasks among themselves. He explained:

There isn't like a very rigid org structure, and people are basically put together that have complementary skills and self-manage....There's nobody telling: You've got to do this and you've got to turn it in at this time. You, as a team, basically say, "Okay, this is what the project needs; here's my strengths and here are areas that I want to improve upon." So, you know, you can stretch yourself as much as you like. And then, as a team, you figure out what needs to be done and get it done.

Center members in the US stated it was imperative to be flexible and take on tasks that were outside their work descriptions and formal roles. Illustrating this, one member emphasized how working at the Innovation Center and using 90-day cycle were similar to working in a start-up, where roles are dynamic and everyone is expected to contribute to the execution of various tasks. He said:

You can't have somebody specializing in a role; you have to wear multiple hats, ...you have to be willing to also pick up other things, and you have to be willing to do one thing one week and another thing another week. You're used to taking a look at what needs to be done this week and volunteering for things, even if it's not your expertise. So, that kind of attitude is necessary.

In addition to feeling that the 90-day cycle promoted a looser, more flexible structure, US team members experienced having agency in redefining and adapting the process, depending on the circumstances and how the work proceeded. Rather than experiencing the 90-day cycle as 
set in stone, Center members in the US assumed that they had the ability and right to define and redefine its content and meaning. They argued, for example, that the number of days was actually somewhat flexible. One member in the US said, "I think that's a huge accomplishment for us to prove this works in 90 or 95 days, whatever the exact number is." Another member described being responsible for the initial user research, and that the project team had decided that that stage should be removed from the 90-day cycle - a decision that extended the actual product-development time considerably, but was seen as perfectly within the purview of the project team to decide.

Another feature of how the US Center enacted the 90-day cycle was their acceptance of the inevitability of failure. They experienced the shorter development cycle as a trial-and-error process, where more ideas could be explored and prototyped, but also more projects would be terminated at an early stage_- "killed," as many said. To team members, failure was not something negative; rather, it was a normal and necessary part of the innovation process. As one manager explained, it was important to have the mindset that sometimes throwing away work is necessary as part of the learning process and to make progress. He said:

You have to be willing to have the mindset that, I'm going to spend my time this week building stuff which may be completely thrown away next week, but that's okay because we've gotten some insight, which will make a better product.

This tolerance for failure was echoed in our conversations with US Center members, who often talked about how the Innovation Center, and particularly the 90-day cycle, implied having "the courage to fail," and "fail often and fail early," because the time investment is relatively modest. One team member, who was also a product lead, described how the 90-day cycle supported an early discovery of imperfect product ideas:

But you don't invest that much up front because it... after 90 days, you figure out, you know, that's not really working, it's not really.... Yes, we spent 90 days, 
10 people's time, you know, but it's not a huge investment, especially not if you look at the scope.... So, and I think it has to do with that concept that, yes, we would be allowed to fail... This is a completely new concept within [InnoTech], to have the luxury almost to fail with something.

In summary, the US Center's enactment of the 90-day cycle reflected a belief in the ability of this practice to foster innovation through more dynamic coordination and looser structures, in which employees had agency and authority to make things happen. The US site's enactment also drew heavily on the reasoning that shorter cycles invited and demanded more iterative processes, in which failures were inevitable and necessary for learning and innovation.

Enactment of the 90-day cycle at the China site. In contrast with the US site, where the 90-day cycle was understood and enacted as a vehicle to modernize ways of working within the organization, the Center in China made sense of the 90-day cycle (or "90-day challenge," as a member referred to it) by viewing it largely as a way to increase efficiency. As one member in China described it, the 90-day cycle would enable them to think about "what kind of time we can prevent to waste." Along similar lines, a Chinese developer elaborated on how the 90-day cycle would enable the Center to showcase their efficiency to other InnoTech sites. He said the Innovation Center would "create that kind of challenge to let us to prove that we can achieve a project or finish a project in maybe less than 90 days." Along similar lines, another Center member in China argued that he liked the shorter development cycle; he considered it a challenge that would motivate members to work harder and be more efficient due to a tighter deadline. He also thought this higher level of efficiency would enable InnoTech to keep up with the competition. He said:

Sometimes because people's nature seems... we are lazy, so we don't want to do it very hurriedly, but I think we can do it in a short time. So, it's a very good idea, especially these days, everyone need to do things quickly because we... have a lot of rivals, like other companies, they will, yes, we have a lot of competition. 
Thus, the members at the China Center understood the 90-day cycle as being aligned with their hardworking approach, and saw this as an opportunity to demonstrate their efficiency to colleagues at other locations. This increased efficiency was also perceived as a way to remain competitive and contribute to InnoTech's success. Interestingly, since those at the Chinese Center experienced the 90-day cycle as aligned with their pre-existing approach, they argued that, despite it being a new practice, it did not change the way they worked. As one developer who worked particularly with user interface design, told us:

From my point of view, the change... is not too much different from normal development because we end... one cycle and then start another cycle. And, from my experience, it is not too much from normal development times.

Our observations confirmed that little changed in members' way of working at the China Center relative to the introduction of the 90-day cycle.

Although the China site did not change the way they approached their work, they still worried that the 90-day cycle would lead to negative outcomes. They felt that, since the development time was radically shorter, it forced them to choose only a few features to incorporate into an application to be able to launch it on time. As one junior designer at the China site explained, "Because we have limited resources,... so we can only make one or two functions." The Center members felt that having fewer functions would negatively affect InnoTech's performance in the Chinese market. A member expressed the this concern, arguing that this was a risky approach and could potentially challenge InnoTech's status in the market: the 90-day cycle would lead to releasing products with fewer appealing features, thus making them unattractive to Chinese customers. She also suggested that the time to understand customer needs would be cut short:

Yes, I think it's a very tight schedule ...to deliver an application, even a small application, even a small function from... within 90-day cycle because from 
the...first, I need to include the customer research. I think for myself, I want to deliver an application, which it will be popular....So...they can do a lot of...do more customer research to make sure what we will...deliver is really meaningful.

One intended purpose of the 90-day cycle was to identify applications, early on, that were not likely to succeed in the market, so the organization could change course. This short timeframe stood in contrast to the many years the teams traditionally spent developing applications. As described above, the US members of the Center welcomed this new approach and "failure" as part of a learning process. Those at the China Innovation Center, however, were afraid Chinese customers would lose confidence in InnoTech if a product was terminated after the initial 90 days. They argued that this approach could potentially jeopardize InnoTech's status in the market. One Center member said, "If we would fail, the customer would be angry and we would lose him." Along similar lines, referring to the lack of tolerance for failure, China Center members stated that their project "just cannot go wrong." Hence, members in China had difficulties adopting the "fail early, fail fast" mantra espoused as part of the 90-day cycle. Instead, the Chinese market dictated another belief system that implied products and projects always had to succeed.

In sum, in contrast to the US site, the China Center enacted the 90-day cycle as a vehicle to increase efficiency and perceived it as dependent on clear plans and structure rather than emergent and dynamic processes. Rather than enacting more dynamic and flexible work processes, as was done in the US, those at the Center in China reinforced traditional roles and hierarchical structures. China members articulated that role flexibility was not something they unequivocally considered a positive thing. The China Center's concerns with efficiency also led to apprehensions regarding the lack of fit between the 90-day cycle and the particularities of Chinese customers and market. 
Enactment of the 90-day cycle at the India site. In India, the 90-day cycle was understood in ways we did not encounter in the US or China, especially with regard to enabling customer engagement and better aligning with the larger software developer community. One way that members at the India site understood the 90-day cycle was as a way to engage quickly with customers. A developer told us that the aim of the 90-day cycle is to "create products very fast, as fast as possible, and to showcase it to customers." Immediate and early customer feedback was a crucial aspect of how the India Center members understood the value of the 90day cycle. As the project manager in India described it:

Because we come up with a concept, we finally see the product at the end of 90 days, and that's there in the market. It's not that just you have a product and it's not in the market; you have it in the market, and you already are in the process of selling it to the customers, where you get a chance to talk to the end customers.

Along similar lines, a developer who was also a product lead described how the shortened cycle allowed for development of tangible products that facilitated prompt interaction with customers:

It's 90 days, you have to do a lot more, compared to what you normally do. But I think that is...I think the good thing is it works in the consumer space. Because for every developer who works, you know that they are seeing the effect immediately.

In addition to viewing the 90-day cycle as a way to obtain more rapid interaction with and feedback from customers, several Center members in India framed the 90-day cycle as a way for the India site to align more with the larger community of software developers outside of InnoTech that is moving toward shorter cycles_-particularly in the well-known Silicon Valley. As one developer at the Indian site stated:

An app like this shouldn't take more than 90 days to deliver because when comparing the Bay Area guys iPhone and all these kind of app developers in the California, and these guys develop like within a week...

Along similar lines, a developer at the Indian site explained how the 90-day cycle resonated with 
praxis of other large companies in the industry:

A lot of big companies are following this kind of strategy; they don't want to waste a lot of time, like one year, two years, no. They are shortening, like, six months or four months, four, three, four months, they want to develop something and give to the customer, get their feedback, and immediately put that feedback into the next product cycle, and this is working.

Focusing on getting customer feedback and aligning practices with the larger software developer community led members at the Indian site to embrace the 90-day cycle.

In summary, the Indian site understood the 90 -day cycle as valuable in providing opportunities to obtain customer feedback. Thus, the boundaries between the 90-day cycle and user-centered design were somewhat intertwined for the members at the India site. Those at the Indian Center also experienced the 90-day cycle as a way to allow better alignment with the global community of software developers.

\section{User-Centered Design}

User-centered design was another cornerstone of the Innovation Center concept at InnoTech. User-centered design refers to the incorporation of the user perspective throughout the design process through methods such as interviewing users and inviting user feedback on early prototypes. Management argued that user-centered design was a way for the company to develop products that would also be appealing for and provide a rich experience for users. One manager explained that traditionally, when users were not involved early in the process and the process was governed by a long specification document, a product could be functional in the sense that it fulfilled all the criteria as specified in the document, yet provide a bad user experience. The move towards user-centered design was aimed at addressing this issue. As one manager said "I think we've had the notion too often that we bring something to market that, for whatever reason, wasn't what users need. In other words, we brought it too late and then the wrong thing." User- 
centered design was aimed to remedy this by, as one manager explained, doing "formal user

research," for example, "interviews with influencers" and "lead users,"

In the next section, we discuss how user-centered design enactment differed between the three Centers.

Enactment of user-centered design at the US site. Center members at the US site did not see being user centered as something radically new. Members talked frequently about "customer engagement" in their daily work, referring to "user-centered design," "user research," and "customer interviews" as bases for decisions about product features or alterations. A discussion between two project team members vividly illustrates how the user perspective permeated discussions:

Team member 1: I still favor the user experience, the touch pad experience....I am looking at it, I tap it, the numbers show up. I tap it again, the numbers would disappear. I think it's pretty...it's less frequent, and [the customer] wants to see all the numbers... once for him to do the math.

Team member 2: Yeah. I feel like we're making some assumptions there, that he doesn't want to compare, because I don't think we explicitly asked him that question.

The project team assumed that their task was to uncover problems consumers might experience when the product went to market. As one manager described it, user research was a way to understand problems consumers might experience and to get insights for suitable solutions:

These are some of the values, right, you know. To be insight-driven, but what that means is going out, talking to customers, getting the customers' needs and where they are, and their context, and understanding those and bringing that into our solution development.

We also observed how the US site's desire to engage with customers and acquire honest and straightforward feedback manifested in practice. This is illustrated by an excerpt from an interaction between a Center member and a customer, in which the Center member responds to some negative feedback. He says: 
No, no. This is exactly what we want to hear. Don't say any "sorry." We want your honest feedback...If you don't get it, that means we didn't do good enough job.... We don't want a sugar-coated response to this, we want your unfiltered, authentic response.

Authentic user feedback was seen as a conduit for crafting better products and fueled the usercentered design process. Consistent with this, Center members in the US talked frequently about how and when they could and should acquire user input, and which customers to involve. This was illustrated during an all-hands meeting, when a participant asked, "So, which customers do we want to engage and target, and when in the cycle?...How many and when?" Along similar lines, one designer explained how different customers were involved in different phases of the development:

So, advisors are sort of the less time-intensive folks that come in perhaps...focus group, or perhaps... an event, they give you some input to a prototype. Then, review customers. We brought them into actually monthly sprint reviews... And then, we had design customers. So, literally, we'd go to their location, meet with their user

The user-centered design process in the US extended beyond the actual design of a product to its market launch. The members at the US site argued that customers who had been active participants during the development phase were important ambassadors of the product in the go-to-market phase, and that customer participation in this phase would facilitate market entry and promote success. One member explained:

Because customers that are happy having a voice in the development process, presumably or hopefully - if you do things right - are also customers that are going to become promoters of the solution and your first adopters. And so, the earlier you bring these people into the process, the better-right?

A manager told us that reliance on users in the go-to-market phase was imperative.

Those at the US Innovation Center enacted user-centered design as a vehicle to acquire a better market orientation and keep the needs of customers constantly in mind. Those at the 
Chinese site, however, interpreted and experienced it quite differently.

Enactment of user-centered design at the China site. At the outset, those at the Center in China were largely unfamiliar with user-centered design, and our observations suggest a continued absence of consideration of users in the development process. A developer at the Center, for example, explained that he did not consider user-centered design as the work of an engineer. He said, "I feel that, because I'm an engineer, I don't want to do a lot of research." This was in stark contrast to engineers at the US site, who saw interaction with customers as a central and desirable part of their role.

The reluctance of the Chinese members to embrace user-centered design seemed to stem from several sources. In contrast with the US, where users were seen as valuable sources of insight, in the Chinese context, users were described as indecisive and inarticulate about their needs, and thus unable to provide viable input. As one project lead in China said, "But because sometimes, our customer...he want this, but really to see that he don't want this, he want[s] that." A developer in China further explained that it was the job of the developers to create the needs in the market, more so than unveiling them:

Because you have to guide the customers, guide the markets to find something new, what has not existed in the market. So, this is part...this is very critical part of our daily work...

It was also argued that Chinese customers would be uncomfortable having people observe them as part of trying to understand their everyday work. One manager said, "But you know, due to the different culture in China, [the] customer... will feel very, very nervous if you monitor them. They will feel angry." Hence, the view that Chinese customers would be reluctant to be involved created resistance to engaging with user-centered design, at least in the ways enacted by the US members of the Innovation Center. 
The Chinese members also argued that they lacked the expertise needed to understand user needs, because users were situated in diverse and highly specialized fields. The excerpt below from a product lead, related to a financial application being developed, illustrates this common view:

But they may not understand: what is the real insights of customers, to talk about their painpoints, because they don't understand the business context, they don't have the domain knowledges of this business. So, I think a lot of people will not understand the financial processes, and also they will face a lot of questions when [they] design... solutions for them.

In addition to skepticism about Chinese users having useful input that could be extracted and understood by developers, the members in China found the constant deviation from specifications, which often resulted when engaging with users, disruptive and inefficient. They even argued that this violated their work principles. The story about feedback in the development process that one developer shared illustrates this particularly well. He explained his frustration with the frequent changes throughout a project because of customer feedback saying: "And I know the plan always change, but we don't like that." He added that this led to numerous problems in the process.

In summary, the user-centered design process in China was understood as placing demands on customers and developers that were in conflict with engineering expectations and practices. The members in China reported that their roles as engineers did not encompass user research, that users were unreliable and unwilling participants in this process, and that constant changes from the iterative process disrupted their ability to deliver good code. Thus, the members resisted and made minimal changes to their practices to incorporate users.

Enactment of user-centered design at the India site. Those at the Innovation Center in India perceived user-centered design as aligned with their existing practices of engaging with 
customers. They frequently told us that, several years earlier, they started to engage in user-

centered design practices. A member in India described how user research became an

established practice after a project using that approach was successful in the market. He said:

The team went and talked to the sales team in India, and they went there thinking this would be some variation of a CRM-like application. And right then, after two weeks of discussions with the end users, when they realized that CRM is not what the users want....So, six months later, they had developed the first version of the prototype....And, at that point is when [the CTO] made the decision that he wants to productize it. Because one, it met a real user need. It looked like there was going to be a generic need of the market, because the initial research and even the follow-up research over the six-month period indicated that, for many of the larger companies, they don't necessarily have such systems in place where the sales reps have these... this kind of information at their fingertips.

Thus, user research was a practice members at the Center in India had already embraced.

What emerged as being particularly characteristic about the way the Indian team enacted usercentered design was their reliance on the community and personal networks to acquire user feedback. Related to the quote above, it was explained, "The team went and talked to the sales team." In our subsequent interviews, we learned that this was an example of their largely informal way of acquiring user feedback: users were defined very broadly, and feedback was acquired through casual discussions or community websites. The excerpt below from an interview with a product lead elaborates:

So, we specified...we put in what we required. So, at one point, we said we are needing people to test..., people to do logo design, to write out... to meet up with engineers, tell the requirements, all these things we put up in the community page. So, people came up, people participated.

Compared with the US site, which targeted and approached users more formally and guided their input by preset questions, the Indian approach was more open and unstructured. Those at the India Center relied on a broader community and on people volunteering input into the design. They reported a strong feeling that potential users were among them, and perceived the 
community's knowledge as valuable and accessible through informal interactions.

Interestingly, unlike the US site, the India members did not frame user-centered design primarily as a way to create more successful products, although that was a desired outcome. Unlike the members in China, the India site did not feel that user-centered design was inappropriate for either engineers or customers. Rather, the India members saw it as a natural way to engage the community in their activities, to be transparent, and to start dialogs. They saw user-centered design as aligned with how they traditionally engaged with the community; they employed a largely informal and unstructured process and relied on volunteers and their personal networks for input.

\section{Open Space}

For proponents of the Innovation Centers, an important focus was to adapt the office space to encourage more collaborative interaction. InnoTech management believed that Innovation Centers would engage in better design and produce more innovative solutions in open office space compared to the cubicle space that traditionally was used throughout the organization. It was also argued that the former space created communication and collaboration challenges. As one manager explained:

There was a notion that it took a very long time to build something, which I think was perceived as largely being a function of distributed development; distributed not only in terms of different locations, but also different buildings, different cubicles, so on. And then, so it's...that kind of combination lent itself to the notion: Okay, we need to remove as many barriers as possible, kinds of physical...you know, bring them all together. Because if you're in the same room, you can have ad hoc conversations. And so, that is removing the physical barriers, removing the disciplinary barriers, and we're having all these disciplines - design, development, architecture, project management-all literally in the same space.

The management argued that the desired features of a space suitable for innovation should incorporate features such as openness and flexibility to foster collaboration across functions and 
roles. Management highlighted the importance of "removing the barriers to communication"physical as well as functional to foster more "ad hoc conversations," which would eventually lead to better software development. They also wanted to create a "workshop style" that they argued would "give the permission to try about anything." In addition, remoteness from the main campus would facilitate freedom of thought. Despite the fact that the space, including the furniture, was designed to be nearly the same at each of the sites, as we see below, the open space was interpreted and used quite differently at the Innovation Centers in the three locations.

Enactment of open space at the US site. The conviction that open space should replace traditional cubicles resonated with the beliefs of the US Center members. Our field notes were filled with examples of a dynamic atmosphere, where members worked in dyads at someone's desk and had spontaneous encounters. Meetings often took place in the social area-in the center of the space- rather than in closed meeting rooms. In our interviews with US-based members, they claimed "the collaboration level at [the Innovation Center] is significantly higher" compared with that at the main campus. One developer said that setting up meetings was much more spontaneous and efficient in the open space; and it would take three or more days to carve out the same meeting time in the traditional space. Frequently, we witnessed those at the US Center bump into each other, engage in conversation, and end up working jointly at one of their desks. Furthermore, we witnessed how members framed the Innovation Center's remoteness from the main campus as positive, stating that this enabled them to focus on their work as developers and innovators, instead of losing time and productivity being involved in organizational politics. One US member told us during our observations, "In the [Innovation Center]...they waste no energy in worrying about this [organizational politics], while at the main campus it is all about politics." Thus, the Innovation Center's remoteness was seen as allowing 
members to focus on developing new innovative products without being disrupted by issues or tasks less central to their work.

Those at the US Center also experienced the rough and rugged aesthetic of the office space, with cement floors and whiteboard walls, as being aligned with the aesthetics of many start-up firms in Silicon Valley or a local university's design thinking lab and evoking a sense of connection to the broader entrepreneurial and innovative Silicon Valley context. A manager explained the motivation behind the rough, unfinished aesthetics of the space: he hoped for a start-up mentality, with a workshop feel that is "kept rough."

In summary, in the US context, the new space was enacted as a collaborative space, and it fostered a collaborative, highly interactive, and dynamic atmosphere. The rough aesthetics made members at the US site feel connected to the local entrepreneurial context, and was perceived as fostering creativity and providing the Innovation Center with legitimacy in the local context.

Enactment of open space at the China site. Our observations of the members in China started five weeks before they moved to the new offsite Innovation Center. This allowed us to gain an understanding of members' way of working in the traditional space before the move. Our field notes from this time are replete with descriptions of how people worked individually at their desks and how silent it was in the office. "Only the humming from the AC can be heard in the office" was a typical way to characterize the atmosphere. Innovation Center members rarely worked in dyads at a desk or in a cubicle, but it happened occasionally. Furthermore, almost all meetings were scheduled, and they took place in meeting rooms. Generally, lunchtime was the only time members interacted informally and socialized at work.

When we asked members of the China Innovation Center what they thought the new Innovation Center facilities would mean to them, they claimed that they were still struggling to 
find a "short and clear definition" of it. We were struck, however, by their frequent mentioning of the new space as a way to solve problems pertinent to projects, and their understanding of the new space as supporting better and more efficient work practices. As articulated by a male product lead, who had been at InnoTech more than five years:

So everybody will be on the same page, know current status, and what is our blocks, what is the most important targets that we need to finish for each week, and what is the long-term goals for the project, and also what is the most important KPI.

The members at the Chinese site were also concerned that the move would entail a risk to the development process. As one developer stated, "It may bring some risk to our projects because when you move something, you need to adjust to the development environment... from hardware to software." When the group eventually moved to the new facilities outside campus, their interaction and collaboration remained largely the same as it had been in the traditional cubicle space, despite being located in an open office environment. The open space did not lead to more interaction or informal meetings. During most of the day, the office was silent and conversations remained uncommon; members continued to conduct most of their work individually at their desks. It was explained to us that open and collaborative spaces were still rather unusual in China, and the members at the Innovation Center were not used to interacting and moving around freely in an open space. As a developer explained in an interview:

You know, because in some companies, like [Company X], we are not allowed to do something like this: walk so freely in the office areas... our policy is we have to stay in our cubicles maybe, yes. It's not a formal policy, but if you just...you always walk around...the admin will come and tell you, "Don't walk around so frequently. Why don't you stay at your place in the cubicle."

One intention with the new Innovation Center in China-with an open office space and only two adjacent meeting rooms (one of which was appropriated by the manager as an office shortly after moving in) — was that the members should use the open space and social areas for 
meetings, and thus engage in a less formal way of coordinating work. The members of the China Center instead complained from the start about the lack of meeting rooms. This resulted in Chinese-based members scheduling meeting rooms on the main campus instead of using the open space and the social areas at the Innovation Center. Finally, in contrast to the US site, where separation from the main campus was perceived as positive and allowing more freedom, the Chinese members experienced the separation as disruptive and isolating, leading many Center members to want to move back to the main campus.

In summary, the work style of the Chinese Innovation Center members remained largely unchanged despite relocating to an open space office. Instead of engaging in more collaboration and interaction, those at the China site maintained their previous work practices in the open space or returned to the main campus. Day after day, we witnessed members working in silence, individually at their desks, only occasionally engaging in any form of spontaneous interaction in the open space. Their ability to solve problems more effectively, as hoped, did not materialize because meeting rooms were not available, they were not comfortable meeting in the open space, and the access to others on the main campus they felt they needed was limited. As a result, they spent more and more time at the main campus instead of at the Innovation Center.

Enactment of open space at the India site. The new practices were officially introduced to the India site in August 2011, but members did not move into the new Innovation Center until October 2011. We were not present at the time of the move, but observed prior to the move and spoke regularly to Innovation Center members in the months following the move and returned five months and eight months later to observe the practices in the new Innovation Center.

Before the move into the new space, the Indian members worked in a traditional cubicle 
space, but the team was highly interactive even in the cubicle space. Frequently, we observed them interact as a community, where not only work but also other activities such as sharing food, looking at personal photos, playing the guitar, and drawing were important elements of their day. Members described their collaborative and interactive ways of working in the cubicle space as a "workaround," where they resisted the imposed partitions and enacted the cubicle space "as if" it were an open space.

When the members of the Center in India moved to the offsite Innovation Center, surprisingly, their highly interactive and collaborative practices did not transfer. Rather, our field notes were replete with occasions where team members worked individually and silently in the meeting rooms, using them as "quiet spaces," while the open office space remained empty. As one member described:

But I don't think we've utilized this whole collaboration the way we have planned it.... The engineers and the, you know, they have gone in the rooms and worked, but I haven't seen so much conversation... kind of out in the open.

The fact that the open space was frequently empty and was felt to stifle conversations was explained as a concern about privacy. One developer in India told us that he could not talk in the open space in the Innovation Center because everyone could hear. Along similar lines, another developer asked, “Everybody can see what I am doing; and how do I get private space?" This led to a situation where most informal conversations instead took place in the closed meeting rooms and involved only a few project members rather than the whole project team, unlike before. The primary difference between the old and the new space was that the cubicle space had allowed for a certain level of privacy. This base level of privacy may have been a precondition for the vibrant and highly interactive work that occurred before. Our observations suggest that when the possibility for privacy was removed, members tried to recreate it by 
isolating themselves in meeting rooms, leading to less spontaneous interaction. As one designer summarized, when talking about how they were using the space, "The entire well of the whole thing is empty."

Unlike in the US, Innovation Center members in India received the start-up aesthetic with skepticism. In an informal conversation with one team member, we were told, "An office should be well taken care of; it shouldn't have things that are broken on the floor." In contrast to the US site, the India members argued that, for innovation to happen, they needed a "clean cubicle that is comfortable, with carpets," rather than "a garage set up, with the flooring of a garage." As one developer told us, if they have to do something "new and out of the box," then they should have a "nice space." The concern over the sparse aesthetic of the Innovation Center was reinforced by the fact that the India members viewed their office space as a showcase for their activities vis-àvis customers. Although it was also seen as a showcase in the US, where the start-up aesthetic brought legitimacy to the Innovation Center, in India it was perceived as an embarrassment and a liability.

Contrary to the US and more like China, those at the Innovation Center in India experienced separation from the main campus as problematic, creating a feeling of alienation from the organization and their colleagues in other teams. We were told, and we observed, that previous connections with others had splintered; members bemoaned the fact that their ties with others at the main campus were weakening.

In summary, paradoxically, those in India had enacted the traditional cubicle space as collaborative and highly communal space; however, when they moved to the Innovation Center, their collaborative practice was disrupted and they felt isolated from others at the main campus. Furthermore, the rough aesthetic did not resonate with the members; they found that it did not 
meet their expectations for conditions conducive to innovative work or hosting customers

\section{DISCOVERING LOGICS AS A BASIS FOR RECONTEXTUALIZATION}

Our findings suggest that the Innovation Center concept, when it was transferred, was made sense of and enacted quite differently at the different sites. We describe above how three practices embedded in the Innovation Centers at InnoTech-the 90-day cycle, user-centered design, and open space — came to take on different meanings and were enacted differently at each site. Similar to Brannen (2004), we noticed a process of "recontextualization" as Center members reinterpreted the practices through the lens of their local context. In Brannen's work, recontextualization is a way that individuals interpret a practice within their particular context and create a meaning that makes sense to them. Brannen's macro-level analysis, however, was not able to identify the particular meaning systems being drawn upon or how recontextualization occurred. Our analysis suggests that the different meaning systems used at each location for figuring out what these practices meant to them were based on logics. That is, the logics provided "meaning to their social reality" (Thornton \& Ocasio, 1999: 804).

We argue that diverse recontextualizations of the practices at the various sites can be seen as manifestations of largely different constellations of logics on which team members drew. Our data show that when professionals are spread across different local contexts they may draw on entirely or partially different constellations of logics. Figures 1a-1c illustrate the processes we observed, in which different constellations of logics were utilized at each location for a given practice. As indicated in the figures, a practice (e.g. the 90-day cycle, see figure 1a) was transferred to a given location (e.g. India) and a particular logic or set of logics (e.g. a market logic and a community logic in the case of India) were invoked to make sense of that practice.

\section{Insert Figures 1a-1c about here.}


As illustrated in figures 1a-1c, the team located in the US drew primarily on an entrepreneurial logic (90-day cycle and open space) and market logic (user-centered design) when enacting these practices. The entrepreneurial logic implies a belief in creativity and innovativeness, suggesting practices such as diversity in thinking, tolerating uncertainty, reframing problems, and acting quickly with a focus on defining and implementing new opportunities and solutions (Barton Cunningham, Gerrard, Schoch \& Lai Hong, 2002). Drawing on an entrepreneurial logic, both the 90-day cycle and the open space practices in the US were enacted as vehicles to use increasingly informal, loose, and collaborative processes and structures, as well as to recognize failure as a learning opportunity, all in the service of becoming more flexible and innovative. Our findings from the US show that the Center also drew on a market logic to make sense of user-centered design. When organizational members draw on a market logic, they are imbued by a belief system governed by self-interest (Thornton et al., 2012), the focus of which is to acquire status in the market and profit maximization and which dictates practices such as acquiring a deep understanding of customers needs. This logic particularly manifested in the way in which the US members made sense of and enacted usercentered design - they saw it as a vehicle for developing better products that would please customers and meet market needs. They also had a strategic way of involving customers that they hoped would lead to advocacy for the product.

Those located in the Center in China, in contrast, relied more heavily on engineering (90day cycle, user-centered design, and open space) and market logics (90-day cycle and usercentered design), which were associated with different enactments of the three practices as compared with the US (see figures 1a-1c). Based on our observations at InnoTech, the engineering logic reflects a belief system grounded in professional expertise, with a focus on 
technological features and their advancement, scientific methods, and practices that follow a scheduled process and adhere to traditional engineering methods and specifications rather than needs and insights generated or expressed by customers. The China members focused on the efficiency benefits of a 90-day development cycle and were skeptical of a user-centered design process that disrupted standard practices. They also preferred to work in a more hierarchical and individual manner, despite the affordances for collaboration offered by the open space. The China members also drew heavily on a market logic, but a somewhat different version of the Western market logic described in the current literature on logics (e.g. Thornton et al, 2012). The Chinese version was based on assumptions influenced by the planned economy, which was dominant in the Chinese context until the 1980s. In short, when a market logic is influenced by beliefs stemming from the model of a planned economy, less importance is placed on understanding customer needs. Instead, centralized production is seen as improving productivity and coordination based on consolidated economic resources (Durlauf \& Blume, 2008). Our findings show that, on one hand, the Chinese Center members enacted the 90-day cycle drawing on elements common in the Western market logic, such as increasing efficiency and keeping up with competition. However, the team also advocated for strict boundaries between customers and producers, which aligns with a market logic of a planned economy where customers have little influence on the actual production. In sum, those at the China Center employed an engineering logic when encountering the open space, and the engineering logic in constellation with the market logic to make sense of the 90-day cycle and user-centered design.

Finally, those at the India site also relied on the market logic (90-day cycle and open space), but drew heavily on the community logic as well (90-day cycle, user-centered design, and open space, see figures 1a-1c). The community logic reflects a belief system based on 
reciprocity where organizations are not only economic actors, but also part of local collectives, focusing on investments and commitments to the community and its values, as a form of “cooperative capitalism" (Thornton et al, 2012, p. 73). For the 90-day cycle, this was revealed in members' focus on the benefits of aligning with a larger development community. In terms of user-centered design, our findings showed that the India site routinely involved individuals from their personal networks and volunteers in the user research. They considered their everyday engagements with the community as part of the user research process. Interestingly, we found that the open space was disruptive to the community logic on which they drew, despite the fact that the intent was to increase collaboration. Although members had collaborated, as well as engaged in activities such as playing music and sharing food, once they moved to the Innovation Center, there was a disconnect between the reality of the space and the community logic on which members relied. As a result, the India site became less, rather than more, interactive.

Finally, the India Center relied heavily on the market logic to make sense of the 90-day cycle and the open space. Members argued that the main benefit of the 90 -day cycle was to obtain immediate customer feedback that would enable them to improve the success of their products. Their negative reaction to the open space was also tied, in part, to a market logic. They argued that the space was unattractive and unsuitable for hosting customers, suggesting that more expensive, professional furniture would be needed to create the image they desired.

\section{Logics and Recontextualization}

What emerges from our findings is an enhanced understanding of the global transfer of practices and how units, when spread across the globe, draw on diverse constellations of logics in order to make sense of a new practice. Our inductive approach enables us to discern the constellation of logics that seemed to matter most at each particular site when engaging with the 
new practice. These constellations of logics prescribe different forms of sensemaking and practices across sites as they are employed in the process of recontextualization. Brannen (2004) argues that language is "a critical part of the cultural context that significantly affects the transnational transfer of firm assets" (595). Our findings align with and extend Brannen's work by articulating the role of logics in this process, and expand beyond her semiotic perspective to incorporate actions as well as meanings.

We rely on our empirical data to depict a more comprehensive view of recontextualization (see Figure 2) by showing how, when encountering a new practice (practice ${ }_{1 . . n}$ ) that is crafted outside of their own context, organizational members in a particular location $\left(\operatorname{location}_{1 \ldots \mathrm{n}}\right)$ draw on constellations of local logics $\left(\operatorname{logics}{ }_{1 \ldots \mathrm{n}}\right)$ to make sense of it. These constellations may be composed of a variety of logics, depending on the context. In our case, we outline how members at the sites invoked four different logics in various constellations to make sense of the transferred practices. The constellation of logics (e.g. the specific combination of $1 \ldots \mathrm{n})$ that members invoke at each site may be entirely different or partially overlapping between sites. In our case, they were partly overlapping since the market logic was prevalent at several sites. For different practices, members at each site may also draw on different logics, thus generating a constellation of logics for a particular practice at a particular location. Traditionally, scholars have tended to view the global transfer of practices as transfers from one national context with one meaning system to another national context with $a$ different meaning system. Our approach suggests that this may be too simplistic of a view and that multiple meaning systems, as depicted in figures 1a-1c, may be invoked when members at a particular site enact a particular practice.

\section{Insert Figure 2 about here}


We also found that various forms of recontextualization were associated with the different constellations of logics that members invoke at each site. The constellation of logics on which Center members draw at a particular site constitute a lens, which makes them attribute various meanings and behaviors to an incoming practice. In some situations, members invoke a constellation of logics that promotes practices that lie close to the origins of the incoming practice, which then require little recontextualization. In other situations, the constellation of logics invoked by the members at each Center promotes practices that are radically different from the intended meanings and actions, which leads members to recontextualize the practice to fit their context. In their recent review on culture in organizational studies, Giorgi, Lockwood, and Glynn (2015) call for more research on culture that incorporates action as well as meaning. In our analysis, we found that both actions and meanings were subject to recontextualization. We saw cases in which the meanings were either recontextualized or not, depending on the logics invoked and how they squared with the intent of the practice. We also saw cases in which actions were recontextualized or not, depending on the logics employed and alignment with existing practices. As illustrated in Figure 3, recontextualization can occur in terms of the degree to which (1) recipients reinterpret the meaning of the practice, and (2) members reinterpret the newly prescribed actions. Our analysis illustrates four forms of recontextualization that occurred at the three sites.

\section{Insert Figure 3 about here}

In several cases, we observed an "absence of recontextualization." This took two forms. The first was when the fit between the meaning and actions associated with the incoming practice aligned so well with those at the recipient site that no reinterpretation was necessary. When participants in the US, for example, encountered user-centered design, they drew on a 
market logic. Their sensemaking of the practice therefore resided close to its origins, and the core meaning remained largely the same (low recontextualization of meaning). At the same time, it was congruent with their existing patterns of behaviors related to the inclusion of users in their development process, so they enacted these practices as prescribed without experiencing a need for recontextualization (low recontextualization of action). Absence of recontextualization can also reflect a scenario in which employees in a given location are unable to invoke a suitable logic to make sense of the meanings or actions associated with the practice and make it legitimate. As a result, they reject the practice without recontextualization. When members at the Innovation Center in China, for example, encountered the open space they invoked the engineering logic, which made the prescribed meanings and actions being transferred incomprehensible to the Center members. Thus, the prevalence of the engineering logic made them unable to reinterpret the meaning of the open space in a way that made sense to them within their own context, nor did this logic provide an imperative for them to change their actions. The practice, therefore, never worked for them and was rejected.

We also observed what we refer to as "reconstrued recontextualization." Reconstrued recontextualization occurs when there is high recontextualization of meaning, but without recontextualization of actions. The China site's treatment of the 90-day cycle followed this pattern. Invoking a constellation of the engineering and market logics, the members at the China site recontextualized the meanings associated with the 90 -day cycle as a way to showcase the team's efficiency internally in the organization. They did not, however, reinterpret or alter behaviors associated with this practice as espoused from the main campus or the US Innovation Center. Instead, they accepted the 90-day deadline, planned tighter schedules, and attempted to make it work for them. Thus, in China the explicit actions associated with the 90-day cycle, e.g. 
completing projects within 90-days, were enacted, but with little of its original intent to create a more flexible and feedback-rich software development practice. Thus, the actions were performed as prescribed albeit with a different meaning attributed to them. Although not present in our data, it is possible that a high level of recontextualization of meaning and low level of recontextualization of action could also result when behavioral patterns are already aligned, so recontextualization of actions would not be required.

A third type of recontextualization was "performance recontextualization." In this case, the meanings remained largely the same as intended with the incoming practice, but the actions were performed differently than prescribed, thus the actions were highly recontextualized. The India site, for example, subscribed to the original meaning of open space as collaborative and interactive, which was aligned with the values prescribed by the community logic on which they drew. Hence, little recontextualization of meaning was needed. Concerns about privacy, however, emerged as critical once they occupied the open space. This led to recontextualization of actions such that those in India reconstituted the expected behaviors to better suit their context. Paradoxically, then, they stopped engaging in the (desired) spontaneous and interactive behaviors that were intended with the open space and had characterized their former way of working. Thus, the meanings were aligned and required no recontextualization, but actions were altered to address privacy concerns.

Finally, we introduce "radical recontextualization," a type of recontextualization that relies on recontextualizing both the meanings and the actions associated with a practice into a local context. We observed radical recontextualization at the US (90-day cycle and open space) and India (90-day cycle and user-centered design) sites. In these cases, both the meaning and practices were highly recontextualized so they resonated with the local cultural context. In the 
US, for example, the 90-day cycle represented an unfamiliar practice, but team members used an entrepreneurial logic tied to rapid innovation to understand it in their context. They applied the prescribed actions in ways that made sense to them - for example, by using the 90 days as a guide rather than a requirement and as a way to experiment more, thus recontextualizing both meaning and action to be aligned with the entrepreneurial logic on which they relied.

\section{DISCUSSION}

As global organizations transfer practices across locations, adaptations are generally necessary to ensure a fit between the practices and the local context (e.g. Ansari et al., 2014). We build on studies related to the transfer (Boxenbaum, 2006; Czarniawska \& Sevón, 1996; Saka, 2004; Frenkel, 2005; Morris \& Lancaster, 2006; Sahlin \& Wedlin, 2008) and recontextualization (Brannen, 2004) of practices by articulating how recipients make sense of and react to practices coming from afar. To date, research has taken a decidedly macro view of the transfer of practices, treating it as a strategic (e.g., Brannen, 2004) or managerial concern (e.g., Boxenbaum, 2006). This macro-level approach has created a gap in our understanding of how units receiving practices from abroad make sense of and enact these practices. By observing innovation centers as they received practices coming from overseas, we are able to better describe what happens at the micro-level. Our analysis suggests that when recipients are faced with an unfamiliar practice, they draw on one or more logics, and the logic(s) they choose varies by practice and by location. The result is different forms of recontextualization where individuals alter either meanings, actions, or both.

Viewing the global transfer of practices from an institutional logics lens, as we have, enables a broader understanding that takes into account how a constellation of field-level logics shapes micro-level, everyday practices at each site. Specifically, the notion of a constellation of 
logics allows us to describe how various logics are drawn upon for different practices in different locations to inform recontextualizaton. We show that logics, therefore, are a crucial source employed to make sense of practices coming from afar. The fact that the team in the US, for example, drew primarily on a market logic when enacting the user-centered design practice made the US Center's recontextualization of the design process look significantly different compared with user-centered design at the Center in India, which drew mainly on the community logic for this practice. Thus, when the ideal of a practice (the practice as it is intended, for example by management) is transferred to other locations, the practice may be recontextualized by individuals who draw upon different logics. We further found that Centers frequently employed multiple logics in making sense of a given practice. China, for example, drew mainly on a constellation of an engineering logic and a market logic in enacting the 90-day cycle and India drew on both market and community logics when making sense of the new open space arrangement. We therefore establish that logics inform the form of adaptation and that multiple logics may be invoked to make sense of a practice.

Our inductive approach using a practice lens enabled us to discern the logics on which employees drew. Our empirical work answers a call to focus on practices as a means to "explain how and why culture influences a range of organizational processes" (Giorgi et al., 2015: 40). Rather than focusing on the legal and regulative systems, or the traits and values, we inductively arrived at the constellation of logics that seemed to matter the most for the members at each particular site when engaging with the new practice. This effort resonates with the turn toward "micro-institutional theory" which, with its focus on "enaction, interpretation, translation, and meaning” (Powell \& Colyvas, 2008: 276), has started to emphasize how actors enact institutions "on the ground" (McPherson \& Sauder, 2013; Thornton et al., 2012), underlining the importance 
of "situated cultural beliefs, norms and behaviors that reflect particular areas of life" (Giorgi et al, 2015: 36).

As a result, we provide insight into different outcomes of the transfer process that are tied to recontextualization of both meaning and action. We propose that there can be an absence of recontextualization, reconstrued recontextualization, performance recontextualization, and radical recontextualization, extending Brannen's (2004) articulation of the recontextualization process at the firm level. We are not the first to try to characterize how employees might deal with competing logics or transferred practices, although previous work has tended to be more theoretical than empirical. In their conceptual paper, for example, Pache and Santos (2013b) theorize that individuals engage in different strategies, including ignorance, compliance, defiance, combination, and compartmentalization, when they confront a new logic. Lücke, Kostova, and Roth (2014) take this a step further by suggesting cognitive strategies that multicultural managers might use when encountering a practice transferred from abroad, including compartmentalization, integration, inclusion, convergence, or generalization. The activities of filtering, repurposing, and coupling were also identified as types of contextualization work done by actors importing practices (Gond \& Boxenbaum, 2013). We see our contribution as orthogonal to the above approaches because our emphasis on practice has enabled us to focus on not the activities or strategies employed in the transfer process, but the variety of outcomes, where either meanings, actions, both or none are recontextualized as the practice is integrated (or not) into the local context. Examining outcomes of the recontextualization process provides a more nuanced understanding of how the fit between incoming practices and the local logics contributes to the form of adaptation. In addition to telling us more about the outcomes of various forms of recontextualization, it suggests when it will not happen. That is, in some cases 
an absence of recontextualization reflected a fit between existing meanings and behaviors and those prescribed by the practice, leading to high fidelity transfers. In such cases, project members invoked logics that were similar to those in the context where the practice was crafted. Absence of recontextualization also occurred when recipients identified no suitable logic for making sense of the incoming practice. In those situations, the practice was rejected. Thus, we argue that it is important to look at the logics invoked as well as the strategies employed to fully understand how practices are transferred and when recontextualization occurs. This also adds nuance to the discussion about whether fidelity or adaptation is desirable, and shows that this is contingent upon the situation. As our findings suggest, under circumstances when logics are aligned (absence of recontextualization and performance recontextualization) fidelity of practices is a reasonable expectation. In other cases, when logics are not well aligned (reconstrued and radical recontextualization) adaptation is a more reasonable expectation.

Our work also raises new areas of inquiry, including questions about the role of recontextualization of meaning and behavior in subsidiary performance and coordination across locations. Most research has focused on fidelity of the transfer. Our data suggest that the highest fidelity transfers occur when meanings and behaviors are already aligned. When the recipient context varies enough that alternative logics are relied upon to make sense of the practice, some form of recontextualization is needed. Questions remain however, about the effect of these forms of recontexualization (reconstrued, performance, and radical) on subsidiary performance.

Questions also remain about what makes a particular logic or constellation of logics salient for a given practice at a given time. Why are members drawing on those particular logics? Are the logics on which units draw relatively stable or are they susceptible to internal (e.g. personalities of members, existing schemas, etc.) and external influences? Rerup and Feldman defined 
organizational interpretive schema as a shared set of assumptions or "knowledge structures that organize past and future experiences" (2011: 578). It would be useful to understand the relationship between logics and these shared schema which may reside somewhere between individual schema and logics and could possibly help to guide the selection of logics. Further, it would be helpful to explore the relationship between strategies used and the logics on which units draw. In other words, are some strategies more effective at producing logics aligned with the original intent of the practice? How can managers support and enable employees to draw on particular constellations of logics in order to create beneficial outcomes? Furthermore, given that our paper suggests that the benefits of fidelity versus adaptation of practices depend upon the situation, we need to better understand how managers can evaluate the trade offs between fidelity and adaptation depending on the context to which practices are being transferred. Finally, our work captures the recontextualization of these transfers, but we do not have data at enough points in time to characterize the unfolding of the recontextualization process. Additional inquiry at a more detailed level will be important for understanding the evolution of the recontexualization process. For example, do recipients of the transfer try out multiple logics and ultimately settle on a few or is it clear from the start which logics will be invoked? We hope that our empirical work provides a foundation for future discoveries along these lines.

Through our research, we also show that in a global context, in contrast to Pache and Santos (2013b), various constellations of logics may exist side-by-side without being perceived as in conflict, yet affect the ways in which practices are transferred. Murray (2010) similarly pointed out the fact that seemingly competing logics can co-exist, although her research was not conducted across contexts. Extending this work, we found another condition when logics can exist side-by-side — when individuals within the same organization carry out their work in 
different geographic locales and are influenced by the constellation of logics prevalent in their local context. Even if the constellations vary across sites (as they did in our study), individuals may not experience competition between logics. Hence, individuals may not consistently invoke the cognitive coping strategies that Pache and Santos (2013b) outline because organizational members need not be aware of the multiple logics. We therefore surface a new line of inquiry into how organizations cope with the recontexualization of practices and multiple logics when competition and institutional complexity are not experienced by its members, yet diverse enactments result. Our findings suggest future research exploring questions about the consequences for globally distributed collaboration when distant workers unknowingly rely on different logics to guide the recontextualizations of their practices. Situations with incompatible practices have been described as challenging and resisting reconciliation (e.g. Cramton \& Hinds, 2014; Nicholson \& Sahay, 2001), but little is known about how having diverse, yet not necessarily incompatible practices, plays out. A lens of institutional logics provides an additional framework to explore these questions.

Related to this, our findings also show that the content of familiar logics may themselves vary across sites. We allude to how the market logic shared some traits across sites, while at the same being characterized by some different features in different locations. We saw, for example, that in the Chinese context, the history of a planned economy seemed to influence the content of the market logic, such that it was different than the market logic in the US. Although our findings only allowed us to see variations of the market logic, this discovery establishes that such variations in familiar logics are possible. It would be reasonable to assume, for example, that the logic of entrepreneurship might look different in different regions given the different composition and use of social networks for entrepreneurial endeavors (Dodd and Patra, 2002; 
Klyver and Foley, 2012). One extension of our work would be to explore how other taken-forgranted logics might vary across contexts.

It is important to note that, along with Brannen, we focus not on adaptation, e.g. how recipients change their own meanings and actions, but recontextualization, e.g. how the practices themselves are reconstituted at the boundary of the local context. This is in stark contrast to how studies on practice adoption (Kostova, 1999; Kostova \& Roth, 2002) traditionally have conceptualized the transfer process, where the practice has been viewed as an entity that is adopted following patterns that lead to either full, minimal, partial or ceremonial adoption (Kostova \& Roth, 2002). The previous focus has therefore emphasized the degree of adoption across sites and deemphasized how a transferred practice can take on partially or entirely new meanings and actions in a new context. The recontextualization perspective thus supports a view of practices as socially constructed and emergent rather than predetermined and stable. We see one of our contributions as extending Brannen's (2004) work and allowing for a view of recontextualization as a multidimensional process. While Brannen (2004) is mainly occupied with how "language produces meaning in situated contexts" (595), we show that a focus on language captures only one part of a more comprehensive process of recontextualization. A focus on language understates the important link between meaning-making and action, and how they are mutually reconstituting. We argue that it is also vital to account for how recontextualization occurs at the level of actions because patterns of actions generate practices (Reckwitz, 2002), which in turn direct attention and inform meaning-making (Giorgio et al, 2015). Meaning is created not only in and through language as semiotics teaches us, but also in the embodied and practical endeavors of individuals (Gallagher \& Zahavi, 2008). This highlights the need for more longitudinal, micro-level studies that focus on practices and recontextualization in situ, 
across a variety of contexts, rather than a primary emphasis on using interviews and archival means to understand the application of logics.

Furthermore, Brannen (2004) assumes that practices are transferred from one dominant meaning system to another. Our logics approach, in contrast, shows that several parallel meaning systems, i.e. constellations of logics, inform recontextualization. One advantage of taking a logics approach to the transfer of practices is that logics account for more situated and local dynamics compared to the notions of national culture and institutional foreignness (see Brannen, 2004) which tend to assume a more static view of culture. Logics provide a language to talk about differences in institutional contexts and how these manifest in the diverse practices within organizations. Thus, employing the lens of logics, especially the cultural "tool box" approach (Swidler, 1986), promotes an understanding that is more sensitive to the elements of culture that matter most in a particular situation, for a particular individual or group, at a particular time. While the values-based view of culture treats culture as stable (e.g. Hofstede, 1984), the institutional logics lens focuses on recursiveness, arguing that institutions are produced and reproduced in the very practices of its members (Jarzabkowski et al, 2009; Thornton et al, 2012). Along similar lines, scholars (Giorgi et al 2015; Perlow, Gittell and Katz, 2004) argue for a recursive view of culture where values and practices constitute and reconstitute each other, suggesting a multi-level view of culture. Such an approach allows a more contextualized view of culture that extends beyond the values-based notion of culture as being in the heads of individuals (Hofstede, 1984, 2001), which has dominated the discussion of national culture in the field of management. We argue that individuals are confronted with a multiplicity of norms, values, routines, institutions, and infrastructures that they navigate in each situation —at various times, different institutions may be dominant in informing the way in which an individual enacts 
a practice. Through our empirical work and by capturing the role of logics in the cross-national transfer of practice, we aim to change the conversation from one heavily dependent on the articulation of cultural values and beliefs in a given national context to one that focuses on logics, which may align with, but are not bound by national borders or cultural values.

Our research also invites future discovery in areas beyond cross-national transfer of practice. In her study of the appropriation of technology within a single firm, Orlikowski, for example, identifies different interpretive conditions, including the "the larger social system within which users work" (2000: 421) and suggests that these institutional conditions affect how technology is integrated into practice. Our results extend Orlikowski's, suggesting that recipients of new technologies may employ a constellation of logics to recontextualize the meanings and actions associated with a technology as it diffuses. Although we focus on transfer of practices across national boundaries as an extreme case, our results may equally apply to domestic contexts that are informed by different logics. For example, strategic alliances rely, to some extent, on common practices across organizations to coordinate effectively (see Pearce, 2015). Based on our findings, it is reasonable to predict that different constellations of logics may be salient within different firms, particularly if they occupy different industries. As a result, the spread of practices within strategic alliances may follow a similar process.

In sum, we have conducted a detailed longitudinal study that suggests the integration of theories related to recontextualization and institutional logics to better inform how practices from afar are experienced by the units that enact them. In doing so, we surface new questions about what guides the selection of logics for the recontextualization of a given practice in a given location, what the consequences are for cross-location collaboration when practices are recontextualized and enacted quite differently across sites, and finally, how do strategies applied 
to the transfer of practice used by organizations and members interact with logics and determine which logics are employed?

\section{REFERENCES}

Ansari, S., Fiss, P. C., \& Zajac, E. J. 2010. Made to fit: How practices vary as they diffuse. Academy of Management Journal, 31: 67-92.

Ansari, S. S., Reinecke, J. and Spaan, A. 2014. How are practices made to vary? Managing practice adaptation in a multinational corporation. Organization Studies, 35(9): 1313-1341.

Barton Cunningham, J., Gerrard, P., Schoch, H., \& Lai Hong, C. 2002. An entrepreneurial logic for the new economy. Management Decision, 40(8): 734-744.

Besharov, M., \& Smith, W. K. 2012. Multiple logics within organizations: An integrative framework and model of organizational hybridity. Cornell University working paper, Ithaca, NY.

Birkinshaw, J., Brannen, M. Y., \& Tung, R. L. 2011. From a distance and generalizable to up close and grounded: Reclaiming a place for qualitative methods in international business research. Journal of International Business Studies, 42(5): 573-581.

Boxenbaum, E. 2006. Lost in Translation The Making of Danish Diversity Management. American Behavioral Scientist, 49(7): 939-948.

Brannen, M. Y. 2004. When Mickey loses face: Recontextualization, semantic fit, and the semiotics of foreignness. Academy of Management Review, 29(4): 593-616. doi:10.5465/AMR.2004.14497613

Canato, A., Ravasi, D., \& Phillips, N. 2013. Coerced practice implementation in cases of low cultural fit: Cultural change and practice adaptation during the implementation of Six Sigma at 3M. Academy of Management Journal, 56: 1724-1753. 
Cramton, C. D., \& Hinds, P. J. 2014. An embedded model of cultural adaptation in global teams. Organization Science, 25(4): 1056-1081.

Czarniawska, B. \& Sevón, G. (Eds.). 1996. Translating organizational change (vol. 56). Berlin: Walter de Gruyter.

Dodd, S. D., \& Patra, E. 2002. National differences in entrepreneurial networking. Entrepreneurship \& Regional Development, 14(2): 117-134.

Dunn, M. B., \& Jones, C. 2010. Institutional logics and institutional pluralism: The contestation of care and science logics in medical education, 1967-2005. Administrative Science Quarterly, 55(1): 114-149.

Durlauf, S. N., \& Blume, L. (Eds.). 2008) The new Palgrave dictionary of economics.

Eisenhardt, K.M. 1989. Building theories from case study research, Academy of Management Review, 14(4): 532-50.

Eisenhardt, K. M., \& Graebner, M. E. (2007). Theory building from cases: Opportunities and challenges. Academy of management journal, 50(1), 25-32.

Ezzy, D. 2002. Qualitative Analysis: Practice and Innovation. Sydney: Allen \& Unwin

Ferner, A., Edward, T., \& Tempel, A. 2011. Power, institutions and the cross-national transfer of employment practices in multinationals. Human Resources, 65(2): 163-187.

Frenkel, M. 2005. The politics of translation: How state level political relations affect the cross-national travel of ideas. Organization, 12: 275-301.

Friedland, R. \& Alford, R. R. 1991. Bringing society back in: Symbols, practices and institutional contradictions. In W. W. Powell, \& P. J. Dimaggio (Eds.), The new institutionalism in organizational analysis: 232-263. Chicago: University of Chicago Press.

Gallagher S. \& Zahavi D. 2008. The phenomenological mind. An introduction to 
philosophy of mind and cognitive science. London: Routledge

Giorgi, S., Lockwood, C. and Glynn, A. 2015. The many faces of culture: Making sense of 30 years of research on culture in organization studies. The Academy of Management Annals, DOI: $10.1080 / 19416520.2015 .1007645$

Goodrick, E., \& Reay, T. 2011. Constellations of institutional logics: Changes in the professional work of pharmacists. Work and Occupations, 38(3): 372-416. doi: $10.1177 / 0730888411406824$

Greenwood, R., Díaz, A. M., Li, S. X., \& Lorente, J. C. 2010. The multiplicity of institutional logics and the heterogeneity of organizational responses. Organization Science, 21(2): $521-539$.

Greenwood, R., Raynard, M., Kodeih, F., Micelotta, E. R., \& Lounsbury, M. 2011. Institutional complexity and organizational responses. The Academy of Management Annals, 5(1): $317-371$.

Hofstede, G. 1984. Culture's consequences: International differences in work-related values (Vol. 5). Sage.

Hofstede, G. 2001. Culture's consequences: Comparing values, behaviors, institutions and organizations across nations. Sage.

Jarzabkowski, P., Matthiesen, J., \& Van de Ven, A. 2009. Doing which work? A practice approach to institutional pluralism. In: T. B. Lawrence, R. Suddaby, \& B. Leca (Eds.), Institutional work: Actors and agency in institutional studies of organizations: 284-316. Cambridge: Cambridge University Press.

Jarzabkowski, P., Smets, M., Bednarek, R., Burke, G., \& Spee, P. 2013. Institutional ambidexterity: Leveraging institutional complexity in practice. Research in the Sociology of 
Organizations, 39: 37-61.

Jarzabkowski, P., \& Whittington, R. 2008. Hard to disagree, mostly. Strategic Organization, 6(1): 101-106.

Jensen, R. J., \& Szulanski, G. 2004. Stickiness and the adaptation of organizational practices in cross-border knowledge transfers. Journal of International Business Studies, 35: 305-523. doi:10.1057/palgrave.jibs. 8400107

Klyver, K., \& Foley, D. 2012. Networking and culture in entrepreneurship. Entrepreneurship \& Regional Development, 24(7-8): 561-588.

Kostova, T. 1999. Transnational transfer of strategic organizational practices: A contextual perspective. Academy of Management Review, 24(2): 308-324. doi:10.5465/AMR.1999.1893938

Kostova, T., \& Roth, K. 2002. Adoption of an organizational practice by subsidiaries of multinational corporations: Institutional and relational effects. Academy of Management Review, 45(1): 215-233. doi:10.2307/3069293

Kostova, T., Roth, K., \& Dacin, M. T. 2008. Institutional theory in the study of multinational corporations: A critique and new directions. Academy of Management Review, 33(4): 994-1006.

Kraatz, M. S., \& Block, E. S. 2008. Organizational implications of institutional pluralism. In R. Greenwood, C. Oliver, K. Sahlin, \& R. Suddaby (Eds.), The SAGE Handbook of Organizational Institutionalism: 243-275. Thousand Oaks, CA: Sage Publications.

Lofland, J., \& Lofland, L. H. 2006. Analyzing social settings. Belmont, CA: Wadsworth Publishing Company.

Lok, J. 2010. Institutional logics as identity projects. Academy of Management Journal, 53(6): 1305-1335. 
Lounsbury, M. 2007. A tale of two cities: Competing logics and practice variation in the professionalizing of mutual funds. Academy of Management Journal, 50(2): 289-307.

Lücke, G., Kostova, T., \& Roth, K. 2013. Multiculturalism from a cognitive perspective: Patterns and implications. Journal of International Business Studies, 45(2):169-190.

Luo, X. 2007. Continuous learning: The influence of national institutional logics on training attitudes. Organization Science, 18(2): 280-296. doi.org/10.1287/orsc.1060.0230

McPherson, C. M., \& Sauder, M. 2013. Logics in action managing institutional complexity in a drug court. Administrative Science Quarterly, 58(2): 165-196.

Morris, T., \& Lancaster, Z. 2006. Translating management ideas. Organization Studies, 27: $207-233$.

Murray, F. 2010.The oncomouse that roared: Hybrid exchange strategies as a source of distinction at the boundary of overlapping institutions. American Journal of Sociology, 116 (2): $341-388$

Muzio, D., \& Faulconbridge, J. 2013. The global professional service firm: “One firm” models versus (Italian) distant institutionalized practices. Organization Studies, 34(7): 897-925. doi: $10.1177 / 0170840612470232$

Nerur, S., Mahapatra, R. K., \& Mangalaraj, G. 2005. Challenges of migrating to agile methodologies. Communications of the ACM. 48(5): 72-78.

Pache, A.-C., \& Santos, F. 2013a. Inside the hybrid organization: Selective coupling as a response to conflicting institutional logics. Academy of Management Journal, 56(4): 972-1001.

Pache, A.-C., \& Santos, F. 2013b. Embedded in hybrid contexts: How individuals in organizations respond to competing institutional logics. Research in the Sociology of Organizations, 39: 3-35. 
Pearce, B. 2015. Alliance Context, Collaborative Dynamics, and Partner Effectiveness. Unpublished dissertation. Carnegie Mellon University, Pittsburgh, PA

Perlow, L.A., Gittell, J.H., and Katz, N. 2004. Contextualizing Patterns of Work Group Interaction: Toward a Nested Theory of Structuration. Organization Science 15(5): 520-536.

Powell, W. W., \& Colyvas, J. A. 2008. Microfoundations of institutional theory. The Sage handbook of organizational institutionalism, 276-298.

Powell, W. W., \& Sandholtz, K. W. 2012. Amphibious entrepreneurs and the emergence of organizational forms. Strategic Entrepreneurship Journal, 6(2): 94-115.

Reay, T., \& Hinings, C. R. 2009. Managing the rivalry of competing institutional logics. Organization Studies, 30(6): 629-652.

Reckwitz, A. (2002). Toward a theory of social practices a development in culturalist theorizing. European Journal of Social Theory, 5(2): 243-263.

Sahlin, K., \& Wedlin, L. 2008. Circulating ideas: Imitation, translation and editing. In R. Greenwood, C. Oliver, K. Sahlin, \& R. Suddaby (Eds.), The SAGE Handbook of Organizational Institutionalism: 218-242. Thousand Oaks, CA: Sage Publications.

Saka, A. 2004. The cross-national diffusion of work systems: Translation of Japanese operations in the UK. Organization Studies, 25(2): 209-228.

Seo, M. G., \& Creed, W. D. 2002. Institutional contradictions, praxis, and institutional change: A dialectical perspective. Academy of Management Review, 27(2): 222-247.

Smets, M., Morris, T., \& Greenwood, R. 2012. From practice to field: A multilevel model of practice-driven institutional change. Academy of Management Journal, 55(4): 877-904.

Spradley, J. 1979. The ethnographic interview. New York: Holt, Rinehart \& Winston. Strauss, A., and Corbin, J. 1998. Basics of qualitative research: Techniques and procedures 
for developing grounded theory ( $2 \mathrm{nd}$ ed.). Newbury Park, CA: Sage

Swidler, A. 1986. Culture in action: Symbols and strategies. American Sociological Review, 51(2): 273-286.

Swidler, A. 2001. Talk of love: How culture matters. Chicago, IL: University of Chicago Press

Szulanski, G., \& Jensen, R. J. 2006. Presumptive adaptation and the effectiveness of knowledge transfer. Strategic Management Journal, 27(10): 937-957. doi: 10.1002/smj.551

Thornton, P. 2004.Markets from culture: Institutional logics and organizational decisions in higher education publishing. Stanford: Stanford University Press.

Thornton, P. H., \& Ocasio, W. 1999. Institutional logics and the historical contingency of power in organizations: Executive succession in the higher education publishing industry, 19581990 1. American Journal of Sociology, 105(3): 801-843.

Thornton, P. H., \& Ocasio, W. 2008. Institutional logics. The Sage handbook of organizational institutionalism, 840: 99-128.

Thornton, P. H., Ocasio, W., \& Lounsbury, M. 2012. The institutional logics perspective: A new approach to culture, structure, and process. New York: Oxford University Press.

Van Maanen, J. 1992. Displacing Disney: Some notes on the flow of culture. Qualitative Sociology, 15(1): 5-35.

Winter, Sidney G., Szulanski, G., Ringov, D. \& Jensen, R. J. 2012. Reproducing knowledge: Inaccurate replication and failure in franchise organizations. Organization Science, 23(3): 672685.

Yin, R. K. 2008. Case Study Research: Design and Methods. Beverly Hills, CA: Sage.

Yu, J., \& Zaheer, S. 2010. Building a process model of local adaptation of practices: A study 
of Six Sigma implementation in Korean and US firms. Journal of International Business

Studies, 41: 475-499. doi:10.1057/jibs.2009.82

Zilber, T. B. 2002. Institutionalization as an interplay between actions, meanings, and actors:

The case of a rape crisis center in Israel. Academy of Management Journal, 45(1): 234-254.

Zilber, T. B. 2006. The work of the symbolic in institutional processes: Translations of rational myths in Israeli high tech. Academy of Management Journal, 49(2): 281-303. 
TABLE 1: Overview of Data Collected by Location

\begin{tabular}{|c|c|c|c|c|c|}
\hline Location & Observation Schedule & $\begin{array}{c}\text { Number of } \\
\text { observation } \\
\text { days }\end{array}$ & $\begin{array}{l}\text { Number of } \\
\text { interviews }\end{array}$ & $\begin{array}{l}\text { Respondent } \\
\text { gender and } \\
\text { nationality }\end{array}$ & $\begin{array}{l}\text { Respondent roles } \\
\text { (engineer/designer) }\end{array}$ \\
\hline China & $\begin{array}{c}7 \text { weeks (summer 2011) } \\
\text { Skype check-ins } 2 \\
2 \text { days (spring 2012) }\end{array}$ & 36 & 13 & $\begin{array}{c}\mathrm{F}=2, \mathrm{M}=11 \\
\text { Chinese }=13\end{array}$ & $\begin{array}{c}\text { Engineer }=12 \\
\text { Designer }=1\end{array}$ \\
\hline India & $\begin{array}{l}5 \text { weeks (summer 2011) } \\
\text { Skype check-ins } 7 \\
1 \text { day (spring 2012) } \\
2 \text { weeks (summer 2012) }\end{array}$ & 30 & $31 *$ & $\begin{array}{c}\mathrm{F}=5, \mathrm{M}=25 \\
\text { Indian }=30\end{array}$ & $\begin{array}{c}\text { Engineer }=28 \\
\text { Designer }=2\end{array}$ \\
\hline US & $\begin{array}{l}2 \text { months (summer } \\
2011 \text { ) } \\
\text { Monthly (fall 2011- } \\
\text { spring 2012) }\end{array}$ & 27 & $\begin{array}{l}12^{*} \\
\text { individual } \\
1 \text { group }\end{array}$ & $\begin{array}{c}\mathrm{F}=3, \mathrm{M}=8 \\
\mathrm{US}=1 \\
\text { Indian }=2 \\
\text { Russian }=1 \\
\text { Chinese }=5 \\
\text { German=2 }\end{array}$ & $\begin{array}{l}\text { Engineer }=8 \\
\text { Designer }=3\end{array}$ \\
\hline
\end{tabular}

Note. $\mathrm{F}=$ female $; \mathrm{M}=$ male

*One team member interviewed twice 
FIGURE 1A: Logics Invoked at Each Site Related to the Transfer of the 90-Day Cycle. When the 90-day cycle was transferred to the respective units (US, China and India), Center members invoked different logics (e.g. the entrepreneurial logic) or constellations of logics (e.g. the market logic and community logic in India) when enacting the practice.

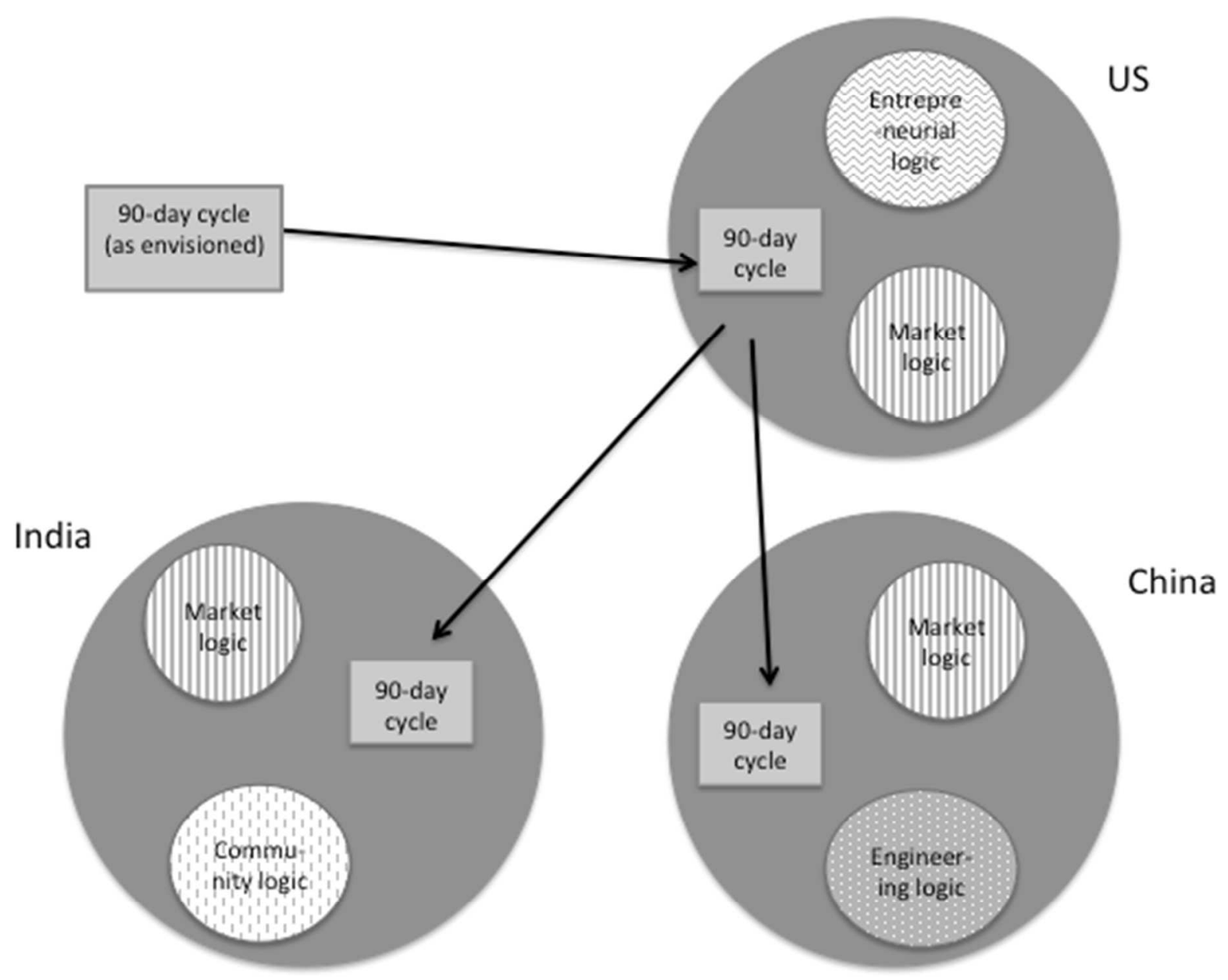


FIGURE 1B: Logics Invoked at Each Site Related to the Transfer of User-Centered Design. When user-centered design was transferred to the respective units (US, China and India), Center members invoked different logics (e.g. the market logic in the US) or constellations of logics (e.g. the market logic and engineering logic in China) when enacting the practice.

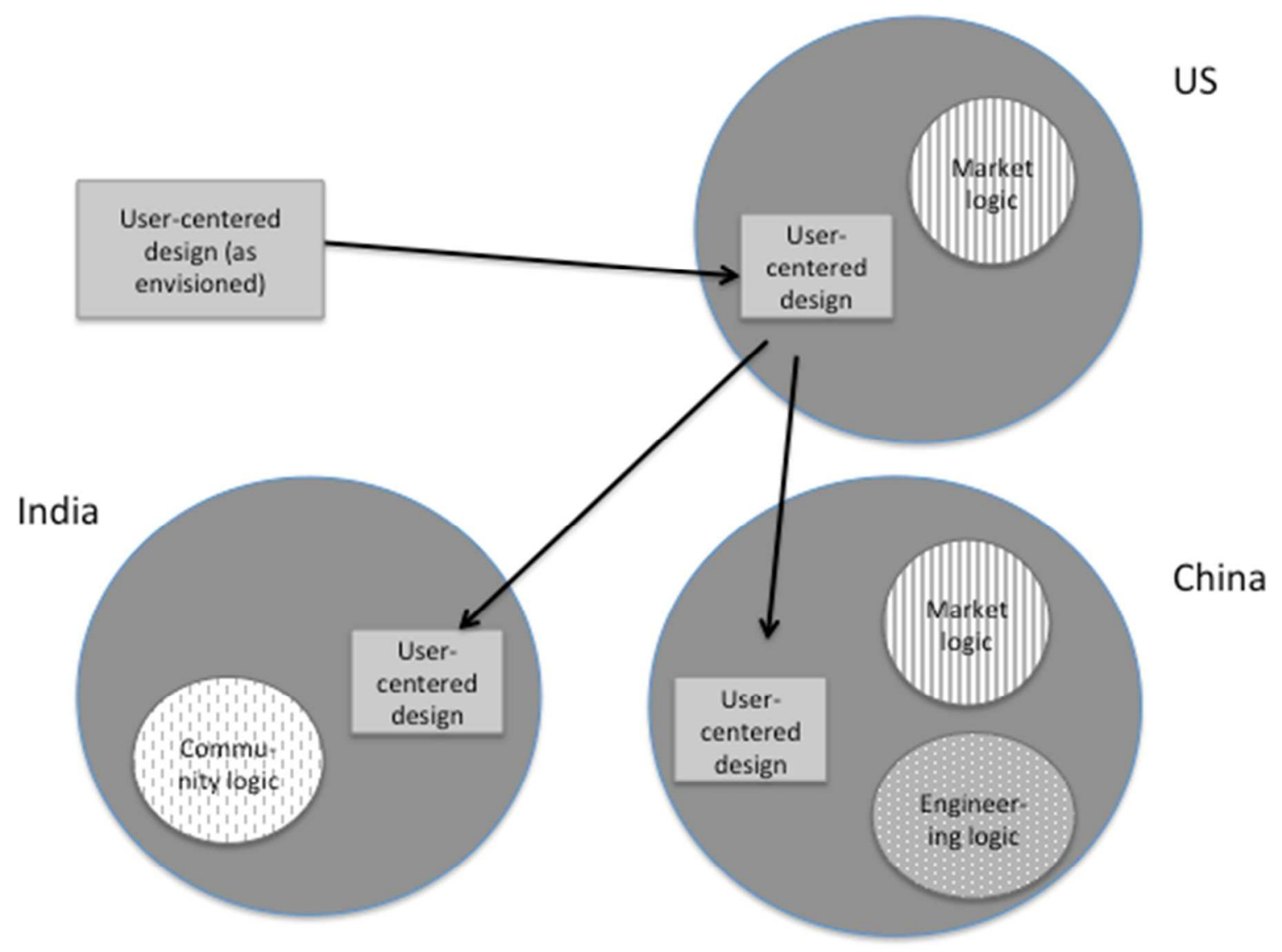


FIGURE 1C: Logics Invoked at Each Site Related to the Transfer of Open Space.

When open space was transferred to the respective units (US, China and India), Center members invoked different logics (e.g. the entrepreneurial logic in the US) or constellations of logics (e.g. the market logic and community logic in India) when enacting the practice.

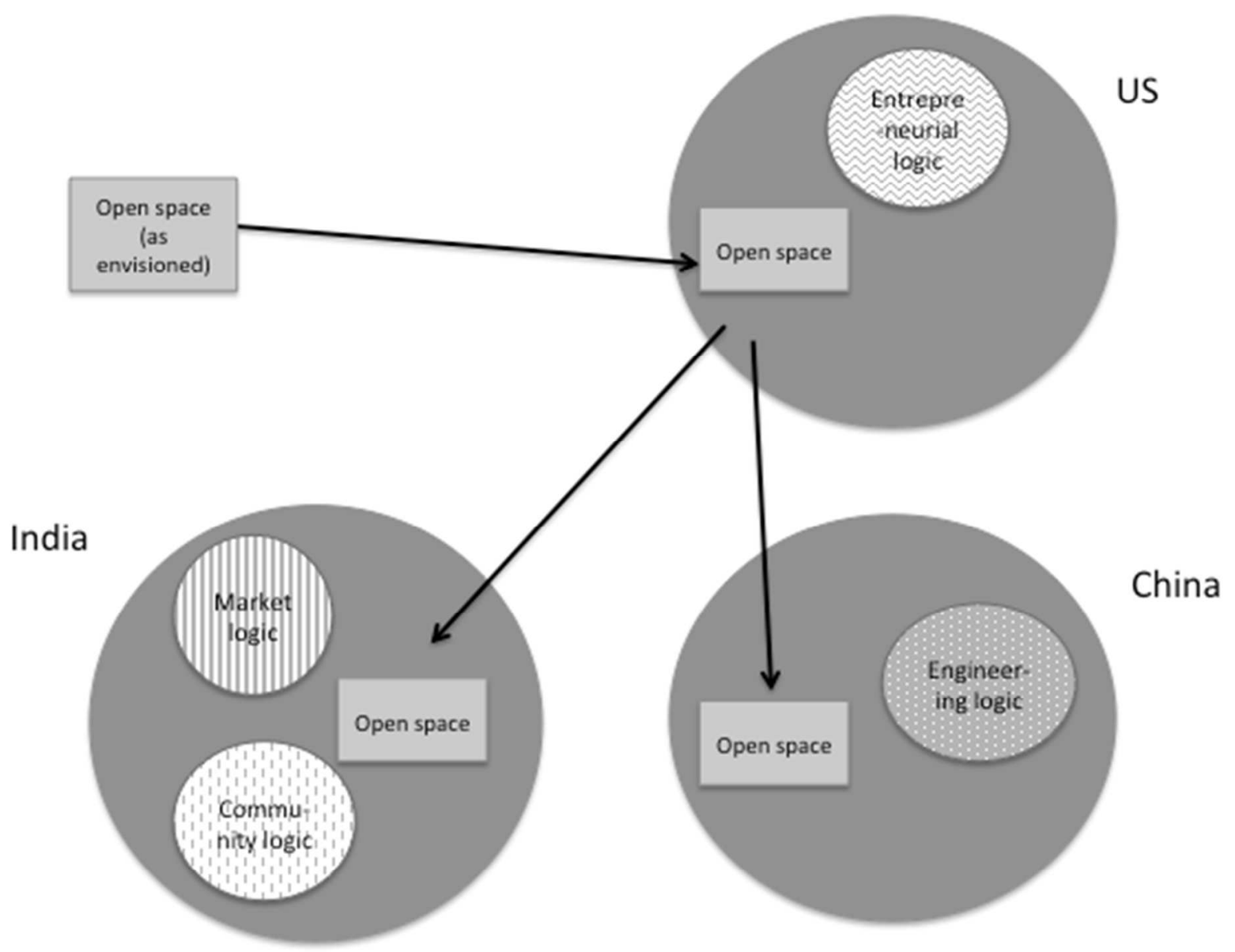


FIGURE 2: The Role of Logics in the Transfer of Practices to Different Locations.

When encountering a new practice (practice $\left.{ }_{1 \ldots n}\right)$ coming from elsewhere, organizational members in a given location (location $\left.{ }_{1 \ldots n}\right)$ draw on constellations of local logics $\left(\operatorname{logics}_{1 \ldots n}\right)$ to make sense of it.

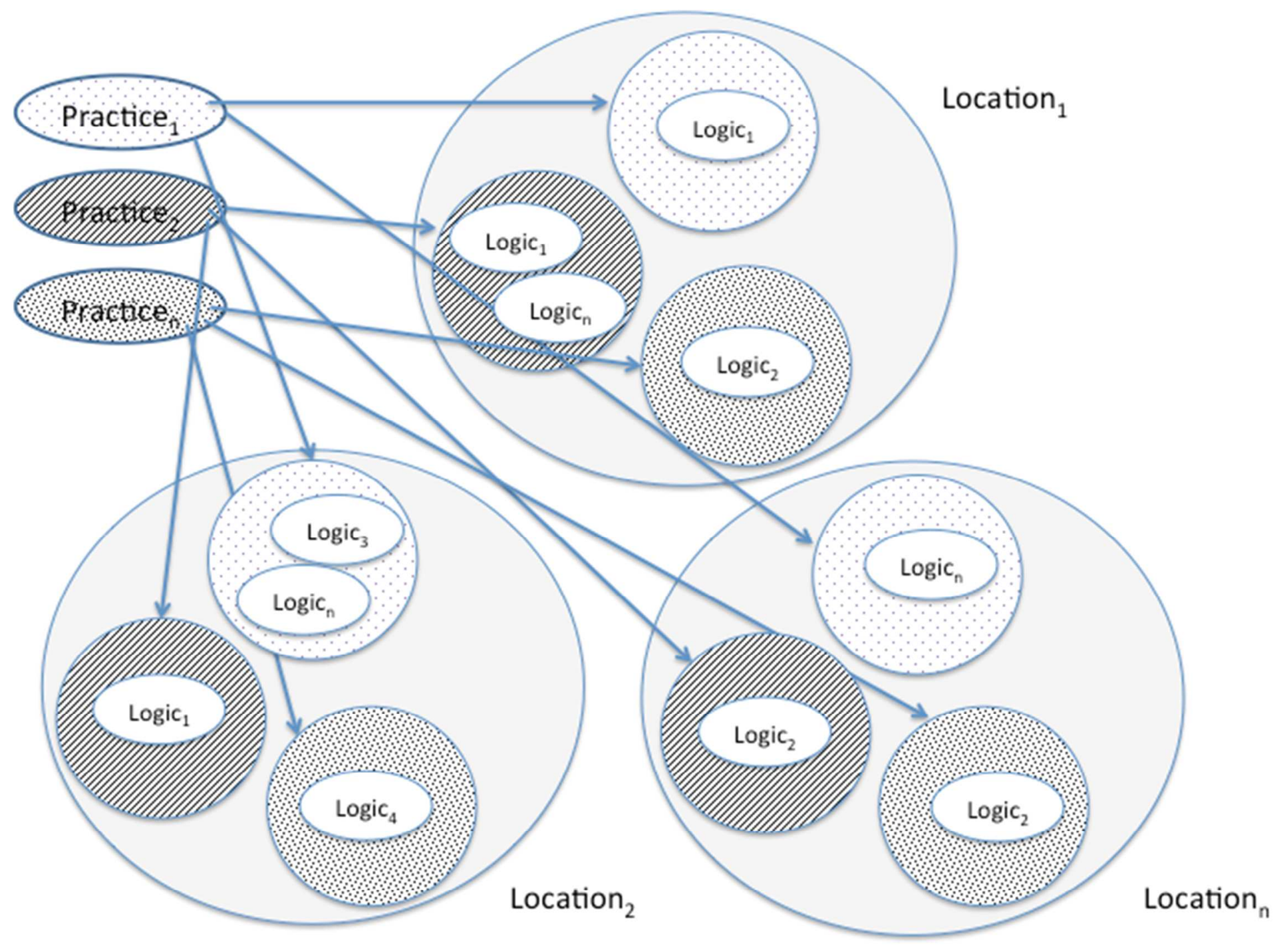


FIGURE 3: Outcomes Based on Recontextualization of Meaning and Action.

With regard to meaning, high refers to high recontextualization of meaning and low refers to low recontexualization of meaning. Similarly, with regard to action, high refers to high recontextualization of action and low refers to low recontexualization of action.

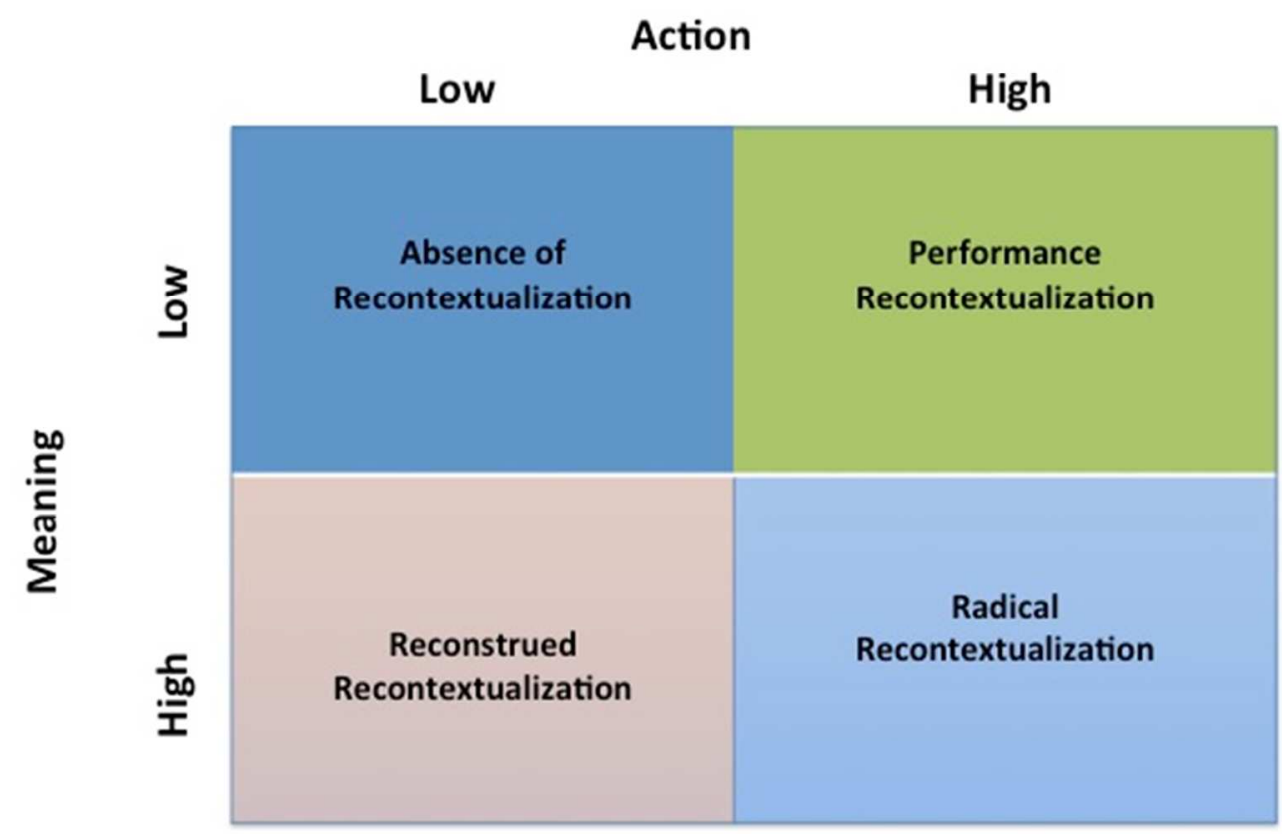




\section{BIOGRAPHICAL SKETCHES}

Sara Värlander, is an Associate Professor at Stockholm Business School, Sweden. Her research revolves around implementation and transfer of new practices in organizations, as well as the processes and outcomes of the implementation of new technology and spatial contexts in organizations.

Pamela Hinds is Professor of Management Science \& Engineering, Stanford University. She has conducted extensive research on the dynamics of globally distributed work teams. Most recently, she has been exploring the relationship between national culture and work practices and between national culture and technology use, particularly use of collaborative technologies. She received her Ph.D. from Carnegie Mellon University.

Bobbi Thomason is a Senior Fellow at the Wharton School at the University of Pennsylvania. Her research broadly examines how individuals experience work and pursue their careers in globalizing and emerging economies. She earned her Ph.D. in Management Science \& Engineering from Stanford University.

Brandi M. Pearce is a Lecturer and the Director of Team Performance and Research at UC Berkeley, Haas School of Business. She earned her Ph.D. from Carnegie Mellon University. Her research broadly explores collaborative dynamics within global organizations. Specifically, she is interested in the collaborative interactions between inter-firm boundary spanners, differences in collaborative dynamics across cultures, and the link between the implementation of collaborative space and individual identity work.

Heather Altman is a PhD student in the Department of Management Science and Engineering at Stanford University. Her research interests include team dynamics in global work environments, in particular how teams coordinate and collaborate to promote creativity and innovation. 